\title{
Utilização de sísmica 4D e de mapas de saturação no ajuste de histórico de reservatórios petrolíferos
}

\author{
Valmir Francisco Risso ${ }^{I}$ \& Denis José Schiozer ${ }^{I}$
}

\begin{abstract}
Resumo O ajuste de histórico de produção tem como principal objetivo calibrar modelos numéricos de campos de petróleo para que os resultados de produção e pressão da simulação sejam coerentes com o histórico de produção e pressão observados e que estes modelos ajustados possam ser usados na previsão de produção com maior confiabilidade. Essa técnica apresenta algumas limitações, principalmente no início do desenvolvimento do campo quando há menos dados de produção observados e as incertezas são maiores, o que torna o processo de ajuste do modelo numérico menos confiável. Com o avanço das técnicas de processamento sísmico e com a sísmica 4D, já é possível a obtenção de mapas de saturação do campo que possibilitam melhorar a qualidade do modelo, possibilitando realizar previsões de comportamento do campo mais confiáveis, principalmente em campos onde a água proveniente de poços injetores ou de aqüíferos ainda não alcançou os poços produtores. Este trabalho propõe uma metodologia de incorporação dos mapas de saturação no processo de ajuste do histórico do campo, combinando estas informações com os dados de produção de óleo, água e gás, de injeção e de pressão.
\end{abstract}

Palavras-chave: Simulação Numérica, Ajuste de Histórico, Mapas de Saturação e Sísmica 4D.

\begin{abstract}
History matching of oilfields using 4D seismic and saturation map. The main objective of history matching is to improve numerical models of oil fields by incorporating observed data, production and pressure, into the characterization process, in order to obtain more reliable production forecasting. This technique presents some limitations mainly in the beginning of the development of oil fields, when less information is available and higher uncertainties are present. With seismic $4 \mathrm{D}$, it is possible to obtain saturation maps allowing the improvement of the numerical model yielding a more reliable production forecasting. The objective of this work is to develop a methodology to improve the numerical model through the incorporation of the saturation maps in the process of history matching.
\end{abstract}

Keywords: Numerical simulation, history matching, saturation map and 4D seismic.

INTRODUÇÃO A complexidade dos reservatórios reais e a conseqüente dificuldade de modelar o problema com precisão através de modelos analíticos fazem com que seja necessária a utilização da simulação numérica que permite obter uma previsão do comportamento do reservatório, com base em um modelo geológico previamente construído a partir de diversos parâmetros gerados durante a caracterização do campo. O problema da modelagem de reservatórios complexos com necessidade de grande precisão é mais crítico em grandes campos marítimos, acompanhados de dados de produção e sísmica $4 \mathrm{D}$, onde são necessárias muitas simulações por análise para calibrar o modelo geológico para que se possam fazer previsões de produção mais confiáveis.

Uma alternativa utilizada no processo de ajuste de campos de petróleo é a utilização de dados de produção e de pressão dos poços produtores e injetores na calibração do modelo numérico, onde resultados positivos têm sido continuamente obtidos. No entanto, essa técnica apresenta algumas limitações, principalmente no inicio do desenvolvimento do campo, época em que a água proveniente de poços injetores ou de aqüíferos ainda não alcançou os poços produtores, o que torna o processo de ajuste do modelo numérico muito mais difícil e trabalhoso. O presente trabalho propõe um método que permita a integração do histórico de produção e de pressão com os mapas das frentes de saturação obtidos através da sísmica 4D.

AJUSTE DE HISTÓRICO DE PRODUÇÃO O principal objetivo de um estudo de engenharia de reservatório é prever o desempenho futuro da jazida, definindo métodos e meios para aumentar, da forma mais econômica possível, sua recuperação final. A simulação de reservatórios é um processo bastante complexo que tem como objetivo estimar o comportamento de pressões, saturações e produções de uma jazida de hidrocarbonetos, através da solução numérica das equações não-lineares que regem o escoamento dos fluidos no interior do meio poroso. O ajuste de histórico tem como principal objetivo calibrar modelos numéricos de campos de petróleo, afim de que os resultados obtidos sejam coerentes com o histórico de produção existente e que estes modelos de caracterização e de escoamento possam ser usados na previsão de produção com a con- 
fiabilidade desejada.

SÍSMICA 4D A modelagem de levantamentos sísmicos em ambiente de reservatório traz subsídios à compreensão sobre fenômenos associados à propagação de ondas sísmicas e seus relacionamentos com as propriedades relevantes do reservatório: mineralogia, propriedades das rochas (porosidade, saturações em óleo, água e gás, permeabilidade, compressibilidade), dos fluidos (viscosidade, composição química, molhabilidade, compressibilidade) e dos fatores ambientais (pressão nos poros, tensões, temperatura), assim como das variações espaciais e temporais desses parâmetros. A modelagem de dados sísmicos sempre foi uma ferramenta muito útil à sísmica de exploração.

Lumley (1994) apresentou uma teoria para monitorar o fluxo trifásico e a pressão de reservatórios de petróleo. Mostrou em um exemplo que, utilizando os dados de amplitude de sísmicas repetidas (4D), é possível monitorar o escoamento e imagear a saturação e a pressão do campo.

Lumley et al (1994) desenvolveram uma técnica para detectar e interpretar as mudanças em reservatórios do Mar do Norte durante a produção de óleo de poços horizontais. O trabalho envolveu engenharia de reservatórios, simulação de fluxo e modelagem e migração sísmica. $\mathrm{O}$ monitoramento da recuperação de óleo envolveu o mapeamento das diferenças entre levantamentos sísmicos realizados aos 56 e 113 dias, com isso foi possível monitorar a expansão da capa de gás durante a simulação de óleo do campo.

Lumley et al (1995) utilizaram múltiplas sísmicas 3D para monitorar o escoamento no campo Duri na Indonésia (óleos pesados). A sísmica 4D mostrou mudanças dramáticas e complexas no reservatório comparados aos dados sísmicos do modelo base. Com isso mostraram que a pressão, a temperatura e a saturação das frentes do campo Duri podem ser monitoradas com 6 levantamentos sísmicos 3D.

Segundo Blonk et al (1998), em muitos, mas não em todos os casos, os dados sísmicos $4 \mathrm{D}$ podem ser usados com vantagem comercial para monitorar as mudanças de fluxo do reservatório e entre os poços. De acordo com Klan et al (2000), o simulador do reservatório é uma ferramenta poderosa para prever como as saturações e as pressões dos fluidos são distribuídas no reservatório no tempo. Esta informação pode ser usada juntamente com um modelo petrofísico para gerar os mapas sísmicos dos atributos que revelam os resultados 4D que se esperariam da depleção, deslocamento, e heterogeneidade.

Segundo Guerillot e Pianelo (2000), os procedimentos de ajuste são usados freqüentemente na produção de reservatórios pra melhorar os modelos geológicos. A idéia deste trabalho original é ajustar simultaneamente a permeabilidade e a impedância acústica do reservatório para melhorar o modelo geológico. Arenas et al (2001) avaliaram o benefício de usar a sísmica 4D na simulação do reservatório. O problema foca especificamente no uso da sísmica 4D no ajuste de histórico.
Cordeiro (2002) assinala que a Petrobras está caminhando para adotar, o conceito do campo instrumentalizado, que utiliza modernas técnicas de aquisição sísmica para otimizar a produção. Os estudos técnicos estão sendo feitos pelo Pravap 19 - Programa de Recuperação Avançada de Petróleo. De acordo com os especialistas, a tecnologia de OBC - Ocean Bottom Cable, pode se mostrar os movimentos da injeção de água, do gás e do óleo no decorrer da produção.

Kretz et al (2002) estudaram a caracterização de reservatórios combinando dados de produção e dados de sísmica 4D e propuseram um novo procedimento de otimização para gerar modelos de reservatórios através de dados geoestatísticos, de histórico de produção e de movimentos de gás a partir da interpretação sísmica 4D.

Segundo Mantica et al (2002), a busca de parâmetros ótimos da simulação para combinar a produção do reservatório e dados de sísmica $4 \mathrm{D}$ é geralmente um problema significativo. Da mesma maneira, Aanonsen et al (2003) enfatizam que o uso de dados de sísmica $4 \mathrm{D}$, conjuntamente com dados da produção em ajuste de histórico de modelos do reservatório requerem que os vários tipos de dados estejam incorporados em uma única função-objetivo que mede o ajuste entre os dados simulados e medidos.

Mitra e Singh (2003) mostram que o efeito da mudança nos parâmetros do reservatório devido à produção tem um impacto direto nos sinais sísmicos.

Segundo Dong e Oliver (2003), a sísmica 4D é um processo de repetição da sísmica 3D de um reservatório que está produzindo e com isso monitorar as mudanças na saturação e na pressão.

Kretz e Sonneland (2004) propõem um método que possibilita a calibração do modelo de fluxo antes que as deficiências possam ser observadas nos poços, de modo que as ações possam ser antecipadas. A idéia básica atrás deste método é modificar os dados de propriedades do fluxo (porosidade, permeabilidade, volume...) ao longo das linhas de fluxo, de modo que as frentes de saturação computadas coincidam com as observadas obtidas através da sísmica 4D.

Mezghani et al (2004) apresentam um esquema de inversão para estimar propriedades petrofísicas, integrando dados de produção e de sísmica 4D na construção do modelo geológico.

Ribeiro et al (2005) utilizaram as informações da sísmica 4D para identificar o avanço dos fluidos e as áreas não drenadas do campo de Marlim, na Bacia de Campos, com o objetivo de melhorar a locação dos poços. As informações foram obtidas através de dois levantamentos sísmicos, em 1986 e 1997, o primeiro com uma fraca resolução vertical, se comparado com o segundo. O estudo mostrou que é possível monitorar as frentes da água desde que o contraste da impedância entre os óleos remanescentes do campo e a água injetada não seja muito alto.

Steagall et al (2005) apresentaram um método para estimar o valor econômico da informação obtida por um novo levantamento sísmico no campo de Mar- 
lim. A estimativa do valor da informação baseia-se no incremento do valor monetário esperado para o projeto com os novos dados da sísmica 4D.

Segundo Arts et al (2006), o monitoramento contínuo 4D de campos de petróleo já é realidade através da instalação de cabos de fundo (OBC - ocean bottom cables). Os dados da sísmica já podem ser enviados para o computador a uma velocidade acima de 20 Terabits/segundo. Este trabalho apresenta um resumo dos primeiros resultados e quais são as futuras aplicações.

Segundo Al-Jenaibi et al (2006), os métodos que podem monitorar o movimento dos fluidos em reservatórios de petróleo têm grande potencial para ajudar no aumento da recuperação de óleo. Os resultados da sísmica 4D, que mostram onde o fluido mudou no reservatório, são obtidos através da diferença de suas imagens sísmicas coletadas em diferentes datas. Os resultados do trabalho mostraram que a sísmica 4D pode monitorar as mudanças de saturação no reservatório. Para avaliar o potencial da tecnologia da sísmica 4D, um teste foi realizado em um campo com óleo remanescente com grande potencial de aumentar o fator de recuperação. A sísmica 4D ajudou a identificar as zonas de óleo remanescente.

Skorstad et al (2006) sugeriram um método simples para melhorar a caracterização comparando os dados de sísmica 4D com os dados da simulação de um modelo base. Para o estudo foi necessário analisar o modelo sísmico e a inversão elástica em duas datas distintas. Os dados foram obtidos de um modelo sintético. Utilizando os dados da sísmica 4D e os parâmetros obtidos pela inversão elástica da sísmica 3D foi possível diminuir a diferença entre os dados do histórico de produção e os resultados da simulação.

Castro et al (2006) introduziram um método para modelar reservatórios integrando dados de diferentes fontes. O trabalho foi aplicado no campo de Oseberg no Mar do Norte. A principal contribuição do trabalho foi a inclusão dos dados de sísmica 4D. O modelo de reservatório deve honrar simultaneamente todos os dados avaliados, tanto os estáticos (dados de poço, informação geológicas e sísmica 3D) quanto os dinâmicos (produção e sísmica 4D), para preservar a sua capacidade de previsão.

Um estudo para integrar dados estáticos e dinâmicos para a caracterização de reservatórios foi desenvolvido por Kretz et al (2002) e Mezghani et al (2004). Os autores integraram simultaneamente diferentes fontes de informação usando método baseada no método da deformação gradual. Neste artigo foi utilizado um esquema probabilístico que integra dados de múltiplas fontes, tais como, dados de poço, informações geológicas, sísmica 3D e 4D e dados de produção, através de uma aproximação que analisa explicitamente a inconsistência e/ou redundância entre várias fontes de dados, o método foi desenvolvido por Hoffman e Caers (2003).

Atualmente a sísmica 4D ou "time lapse" ainda é uma tecnologia emergente e o maior desafio é integrar os resultados dessa tecnologia na modelagem de reservatórios, ou seja, como utilizar essas informações no processo de calibragem do modelo numérico de reservatórios.

No processo de pesquisa feito não foram encontrados trabalhos que tenham utilizado mapas de saturação diretamente no processo de ajuste de histórico, o que demonstra a grande importância do método proposta neste trabalho. A grande maioria dos trabalhos encontrados na literatura, que procuraram combinar dados de produção com dados sísmicos, procurou ajustar o erro (diferença) entre os mapas de impedância acústica ou de amplitude, obtidos através de dados sísmicos produzidos em datas distintas no tempo, como mostra a figura 1. Essa informação é comparada a um mapa de erro de impedância ou de amplitude obtido através da simulação numérica. Para a conversão dos dados de simulação (saturação) em dados de impedância é utilizado um modelo numérico. Este processo é descrito na figura 1.

Os principais problemas encontrados no processo apresentado na figura 1 são: (1) $O$ processo de ajuste exige no mínimo dois levantamentos sísmicos 3D, o que pode tornar algum projeto inviável economicamente, devido ao alto custo da sísmica, principalmente da sísmica com cabo de fundo que pode custar até 10 vezes mais; (2) Após cada uma das simulações numéricas realizadas no processo de ajuste (lembrando que o processo de ajuste é um processo demorado e que exige um número muito grande de simulações), é necessário gerar novamente dois mapas de impedância e com isso calcular o erro entre eles e só depois então verificar a qualidade do ajuste; (3) O processo de ajuste fica limitado à utilização de somente um tipo de informação (sísmica 4D); (4) A conversão dos dados de saturação para impedância depende de um modelo numérico que deve ser desenvolvido ou comprado.

METODOLOGIA A metodologia utilizada neste trabalho tem o objetivo de apresentar uma nova opção no processo de ajuste de histórico de campos de petróleo. Permite o ajuste de mapas de saturação, diferente da metodologia encontrada na literatura que estabelece o ajuste da diferença dos mapas de impedância acús-

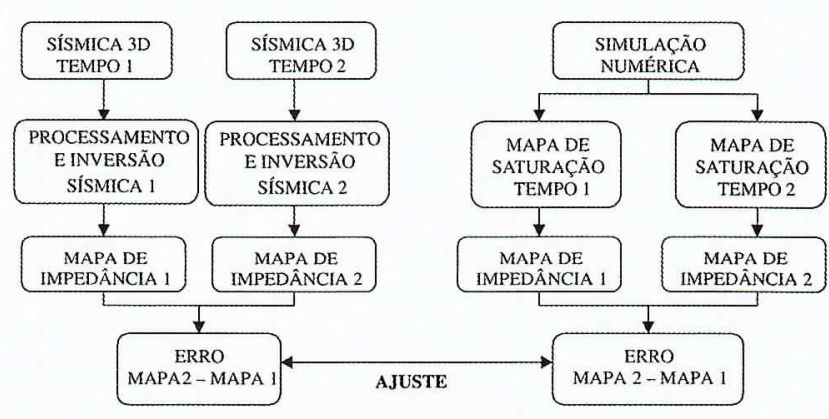

Figura 1 - Metodologia encontrada na literatura, utilizada no processo de ajuste combinando dados de produção com dados de sísmica $4 D$. 
tica.

O processo de ajuste compara o mapa de saturação gerado através da simulação numérica com o mapa de saturação "real", como mostra a figura 2.

As principais vantagens encontradas nesta forma de abordar o problema são: (1) O processo de ajuste exige no mínimo um mapa de saturação para que o processo de ajuste seja possível e não dois mapas de impedância acústica como mostrado na revisão bibliográfica; (2) Não é necessário gerar novamente o mapa de impedância acústica ou amplitude após cada uma das simulações numéricas realizadas no processo de ajuste, pois a qualidade do ajuste é verificada através do ajuste do mapa de saturação que é um dado de saída do simulador; (3) O processo de ajuste independe da técnica utilizada para gerar os mapas de saturação, seja através da sísmica, de perfis de poços ou qualquer outra técnica; (4) Não é necessário desenvolver qualquer modelo numérico, pois todo o processo de ajuste pode ser feito utilizando-se simuladores comerciais.

\section{Modelo Real Modificado - Mapa de Saturação do} Campo Para que os resultados obtidos neste trabalho sejam validados é necessária que tanto os dados de entrada quanto os dados de saída sejam conhecidos. Para isso foi utilizado um modelo real com modificações, o qual é considerado como referência, pois as respostas ajustadas, tais como: produção de óleo, água e gás, injeção de água e a pressão dos poços, bem como os mapas das frentes de saturação, são obtidas através da simulação deste modelo.

Modelo Base - Modelo Inicial O processo de ajuste parte de um modelo base com diferenças em relação ao real modificado. O modelo base é construído considerando-se todas as informações disponíveis do campo para que o comportamento do modelo numérico seja o mais próximo possível do campo real. Para as propriedades modificadas, serão escolhidos os valores mais prováveis de ocorrência de cada atributo.

Mapas de Volume por Unidade de Área Para o cálculo do erro e da definição das regiões críticas dos modelos tridimensionais são considerados os mapas de volume (óleo, água ou gás) por unidade de área. A escolha dos mapas de volume baseia-se no fato de que as regiões críticas são as que têm maior volume e não maior

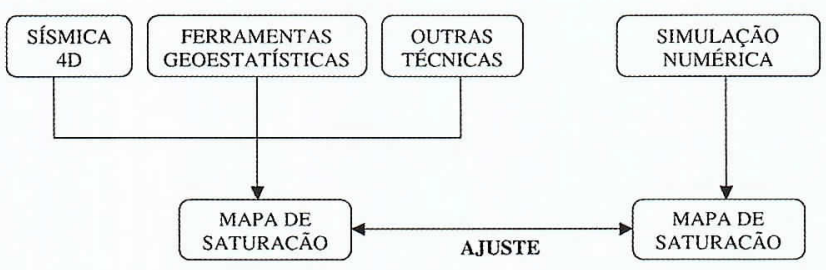

Figura 2 - Processo de ajuste comparando mapas de saturação. saturação, pois o erro nestas regiões tem maior impacto na produção do campo, pois nem sempre a região de maior saturação é a região de maior volume. A equação (1) mostra o cálculo do mapa de volume por unidade de área e um exemplo pode ser observado na figura 3.

$$
\frac{\text { Volume }}{m^{2}}=\text { Saturação } \times \text { porosidade } \times \text { espessura } \quad\left[\frac{m^{3}}{m^{2}}=m\right]
$$

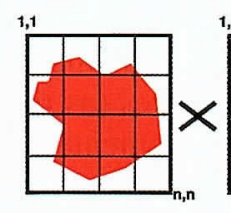

(a)

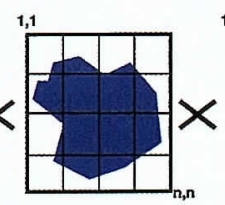

(b)

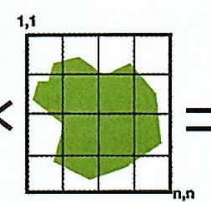

(c)

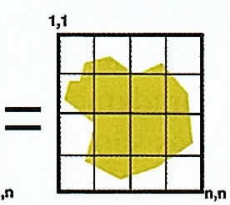

(d)
Figura 3 - Mapa de volume/m²: (a) saturação (b) porosidade (c) espessura (d) volume/ $\mathrm{m}^{2}$.

Mapas de Erro e Regiões Críticas Um mapa de erro é gerado pela diferença entre os resultados da simulação do modelo base e do mapa gerado pelo modelo real modificado. A partir do mapa de erro e de outras informações tais como incertezas, simulação por linhas de fluxo ou outras ferramentas, são definidas as propriedades a serem modificadas no processo de ajuste. Em alguns casos (como no presente trabalho), essas propriedades são regiões do reservatório. É importante ressaltar que o mapa de erro é apenas uma das fontes de escolha das propriedades ou regiões.

As propriedades que têm impacto no processo de ajuste são geralmente chamadas de críticas. Por isso, as regiões críticas são as regiões do modelo base onde são feitas as alterações nos atributos críticos. A equação (2) é utilizada para expressar a diferença em cada ponto da malha através de um algoritmo desenvolvido em MATLAB.

$$
\text { Mapa erro = Mapa simulado }- \text { Mapa real }
$$

A figura 4 mostra um exemplo de escolha das regiões críticas a partir do mapa de erro.

As regiões críticas podem ser definidas individualmente como mostra a figura 4 ou agrupadas, caso

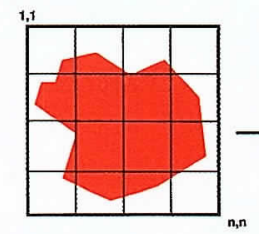

(a)

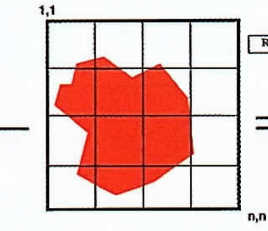

(b)

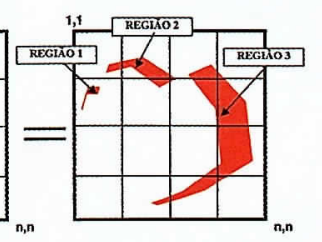

(c)
Figura 4 - Definição das regiões: (a) mapa simulado (b) mapa real (c) mapa de erro. 
tenham as mesmas características, reduzindo o número de simulações necessárias no processo de ajuste ou ainda modificadas de acordo com outras fontes de informações.

Ajuste de Mapas de Saturação A figura 5 apresenta um esquema do processo de ajuste do modelo numérico.

Função-Objetivo A função-objetivo é a resposta que é analisada durante o processo de ajuste e pode ser composta por um único valor (cada resposta é analisada separadamente) ou por um conjunto de valores (as respostas são agrupadas e analisadas simultaneamente).

O processo de ajuste sugerido neste trabalho pode partir de um ajuste global, nesta etapa o erro na produção de óleo, água e gás são medidos em todos os poços produtores do campo, o erro na injeção de água é medido em todos os poços injetores, a pressão é medida em todos os poços (injetores e produtores) e o erro no volume $/ \mathrm{m}^{2}$ é medido em todo campo (todas as regiões). $\mathrm{O}$ ajuste global tem por objetivo identificar os poços e as regiões mais críticas e ajustá-las, porém o erro em regiões menores pode não ser captado pelo ajuste global. Caso isso ocorra é necessário fazer um ajuste local nestas regiões e/ou poços e a função-objetivo é calculada somente nesta região ou neste poço específico.

A função-objetivo mede a diferença entre os dados reais (histórico do campo) e os resultados simulados (modelo base). A figura 6 exemplifica, para este trabalho, o cálculo do erro $(\mathrm{d}=$ afastamento entre histórico e simulação) para os dados de produção, de injeção e de pressão e a figura 4 exemplifica o cálculo do erro (diferença em cada ponto da malha) para os mapas.

A equação (3) mostra a forma geral do cálculo da função-objetivo, a equação (4) mostra o cálculo do erro nos mapas de volume $/ \mathrm{m}^{2}$, a equação (5) mostra o cálculo da diferença entre os dados simulado e real e a equação (6) mostra o cálculo do erro nos poços.

$$
\begin{aligned}
& F O_{G E R A L}=P_{1} \cdot \varepsilon_{P I P}+P_{2} \cdot \varepsilon_{M V} \\
& \varepsilon_{M V}=\sum_{i=1}^{n m} P_{i} \cdot \sum_{j=1}^{n r c} \varepsilon_{R j} \\
& \varepsilon=\frac{\sum_{i=1}^{z i}\left(\text { simulado }_{i}-\text { real }_{i}\right)^{2}}{\sum_{i=1}^{z i}\left(\text { simulado }_{B A S E}-\text { real }_{i}\right)^{2}}
\end{aligned}
$$

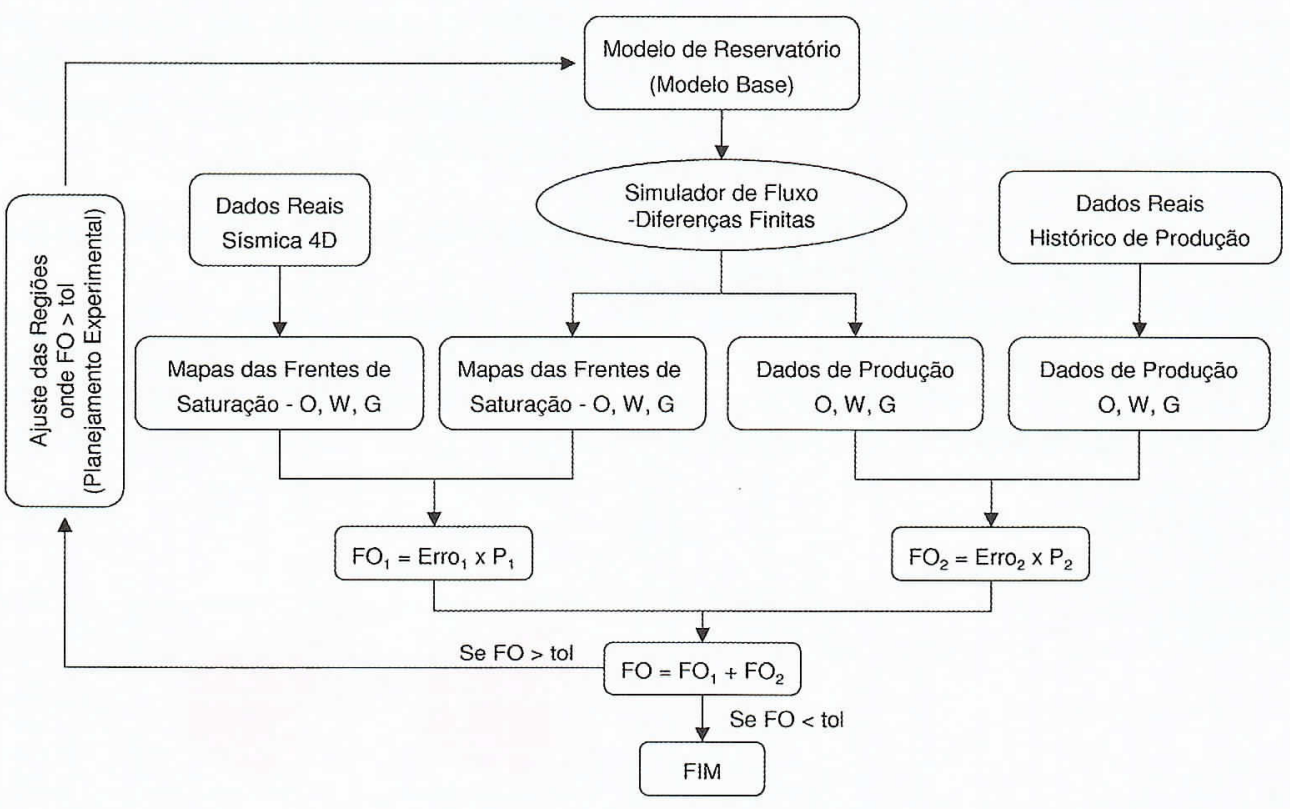

Figura 5 - Esquema considerando os dados da sísmica $4 D$ (mapas das frentes de saturação) e o histórico de produção do campo. $F O=$ Função-Objetivo. $P=P e s o($ $P 1+P 2=1)$. 
APLICAÇÃO A escolha do reservatório, para aplicar o método, levou em conta o fato deste ser bastante conhecido. $\mathrm{O}$ reservatório se situa em um campo na plataforma continental do Rio de Janeiro, Bacia de Campos, em lâmina d'água de 110 a $250 \mathrm{~m}$, a $80 \mathrm{~km}$ da costa. A descoberta deu-se em novembro de 1975 e o volume de óleo inicial do reservatório foi estimado em 108 milhões de $\mathrm{m}^{3}$.

Foi construído um modelo tridimensional do reservatório, como mostra a figura 7, composto por 6 camadas, 52 linhas e 30 colunas com blocos de $150 \mathrm{x}$ $150 \mathrm{~m}$ (9360 blocos). A espessura dos blocos foi variável, tendo sido gerada através da interpolação geoestatística dos mapas geológicos. Os mapas gerados foram: espessura, topo, porosidade, espessura porosa, permeabilidade vertical e horizontal. O modelo de escoamento utilizado foi o "Black-Oil". A densidade do óleo foi considerada igual a $887 \mathrm{~kg} / \mathrm{m}^{3}$. A pressão de bolha foi adotada como sendo igual a $211,41 \mathrm{kgf} / \mathrm{cm}^{2}$. A pressão de referência utilizada foi de $322 \mathrm{kgf} / \mathrm{cm}^{2}$ a uma cota de $-3041 \mathrm{~m}$. O simulador utilizado é o IMEX da CMG (Computer Modelling Group, 2005). Foram utilizados 15 poços no processo de ajuste: 10 produtores e 5 injetores.

Modelo Real Modificado A figura 8 mostra os mapas de permeabilidade horizontal do modelo real modificado. A parte superior é composta pelas Camadas 1, 2 e 3 e a parte inferior é composta pelas Camadas 4, 5 e 6. O modelo original é bastante homogêneo e para a validação foram feitas algumas modificações para tornar o modelo mais heterogêneo, foram incluídos alguns canais preferenciais de fluxo e algumas barreiras.

A figura 9 mostra os mapas de permeabilidade vertical do modelo real modificado.

Modelo Base $\mathrm{O}$ ajuste parte inicialmente de um modelo base. Na construção do modelo base foram consideradas todas as informações disponíveis (dados já conhecidos da região, levantamentos sísmicos, poços perfurados etc.). Os valores utilizados na construção do modelo base são sempre os que têm maior probabilidade de ocorrência. A figura 10 mostra os mapas de

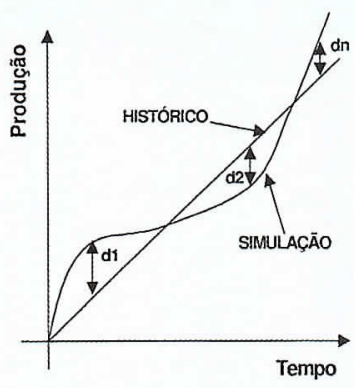

(a)

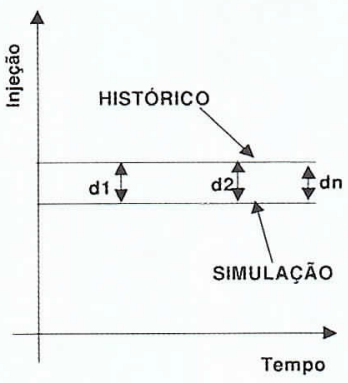

(b)

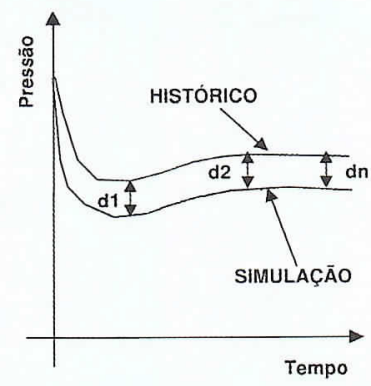

(c)

Figura 6 - Exemplos de cálculo do afastamento medidos entre o modelo de simulação e o histórico do campo: (a) produção de óleo, água e gás (b) injeção (c) pressão.

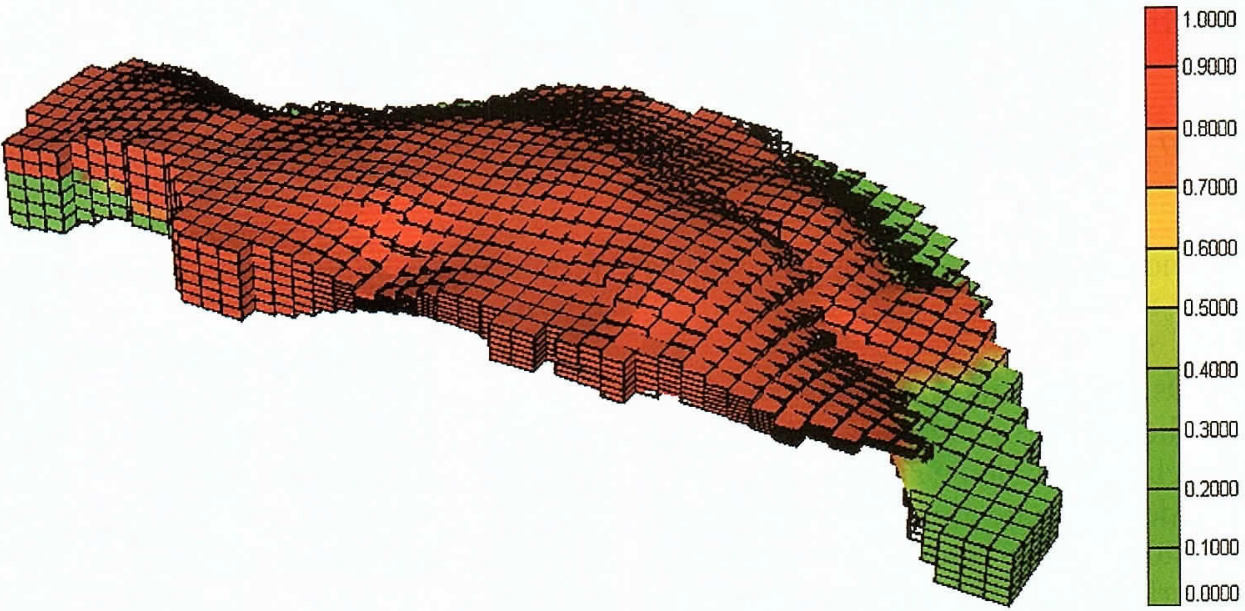

Figura 7 - Modelo geológico 3D do reservatório: mapa de saturação de óleo. 


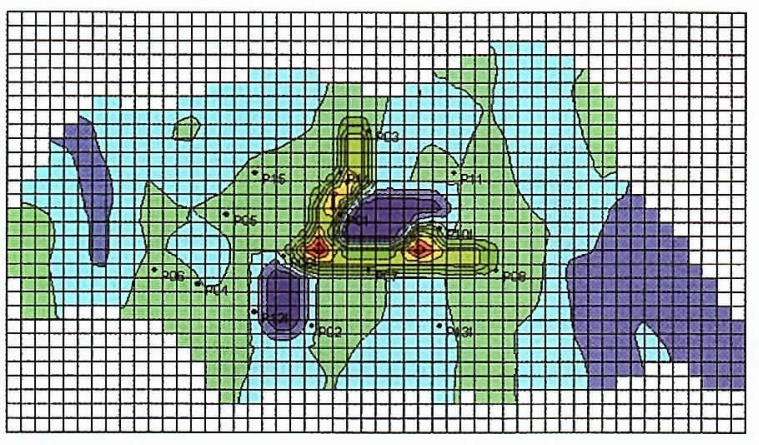

(a)

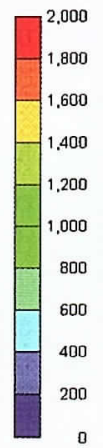

0

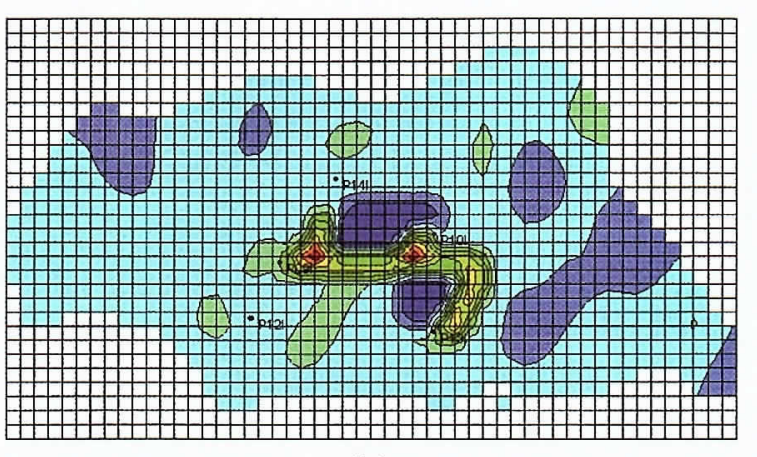

(b)

Figura 8 - Mapa de permeabilidade horizontal do modelo real: (a) parte superior (b) parte inferior.

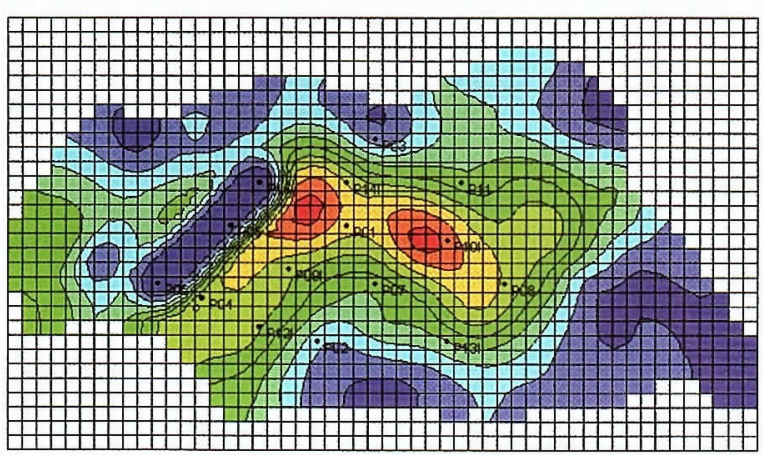

(a)

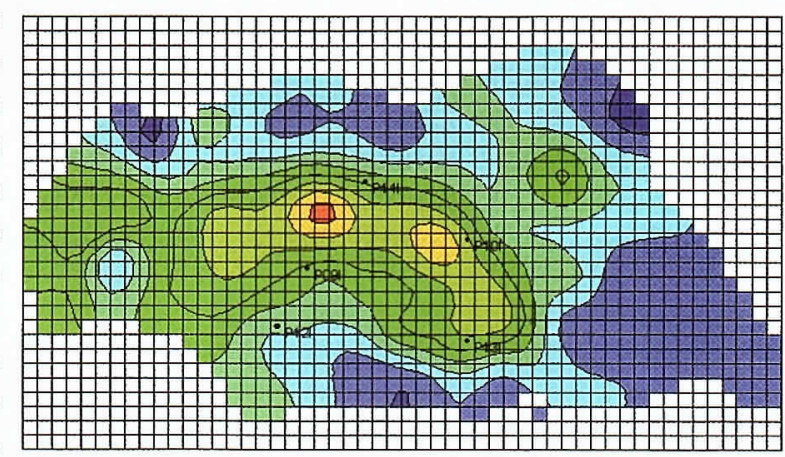

(b)

Figura 9 - Mapa de permeabilidade vertical do modelo real: (a) parte superior (b) parte inferior.

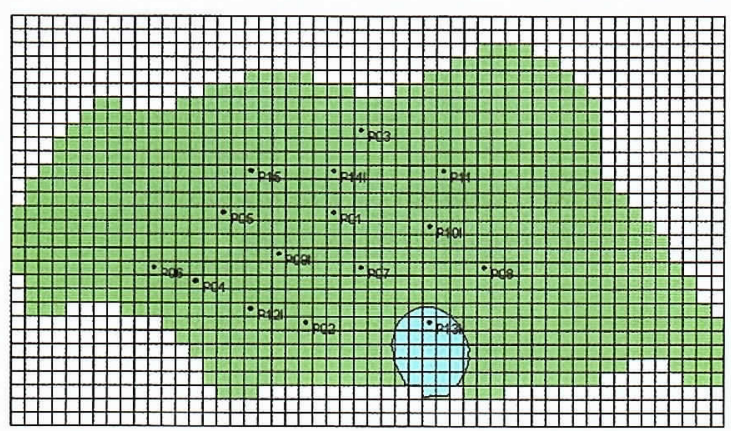

(a)

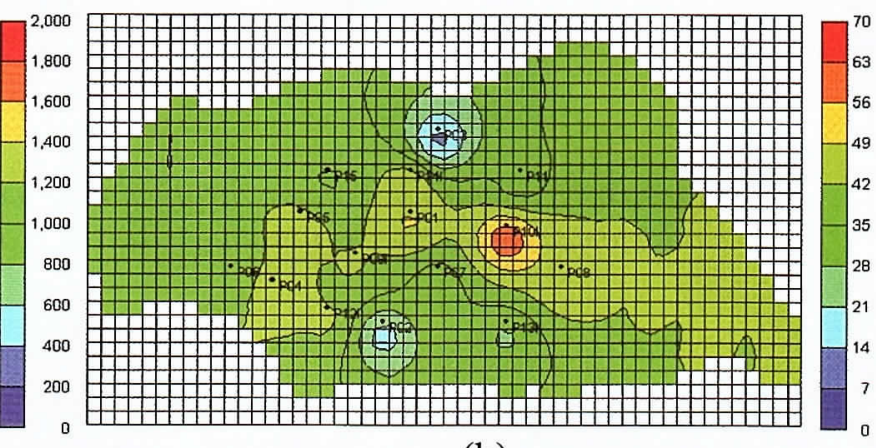

(b)

Figura 10 - Mapa de permeabilidade do modelo base: (a) horizontal (b) vertical.

permeabilidade do modelo base (constante em todas as camadas).

RESULTADOS Os atributos incertos que serão ajustados são: permeabilidade horizontal, vertical e curvas de permeabilidade relativa ao óleo e à água.

O processo de ajuste do modelo real é caracterizado por um histórico de 6 anos. As informações disponíveis neste período são: (1) histórico de produção de óleo, de água e gás dos 10 poços produtores; (2) histórico de injeção de água dos 5 poços injetores; (3) histórico de pressão dos 15 poços. Aos 6 anos de produção é obtido um mapa de saturação do campo, conforme mostra a figura 11 .

O comportamento da produção de óleo e água,

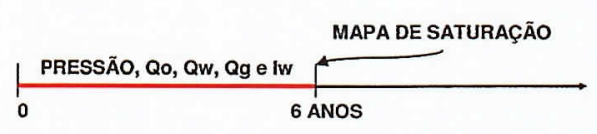

Figura 11 - Período do ajuste do campo. 
da injeção de água e da pressão durante o período de histórico, pode ser observado na figura 12 .

Utilizando os mapas de saturação de água, a porosidade e a espessura dos modelos real e base são construídos os mapas de volume de água e utilizados na definição dos erros existentes, como mostram as figuras 13 e 14.

As regiões críticas, para a parte superior (Fig. 16-a) e para inferior (Fig. 16-b), são definidas considerando os mapas de erro das figuras 13 e 14 e também o

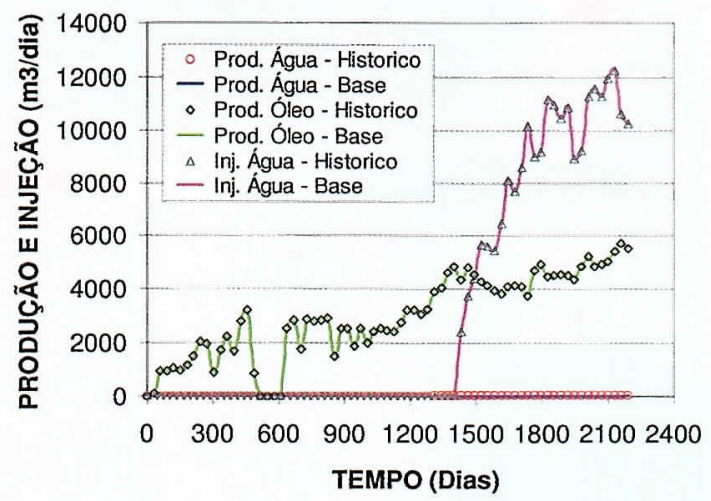

(a)

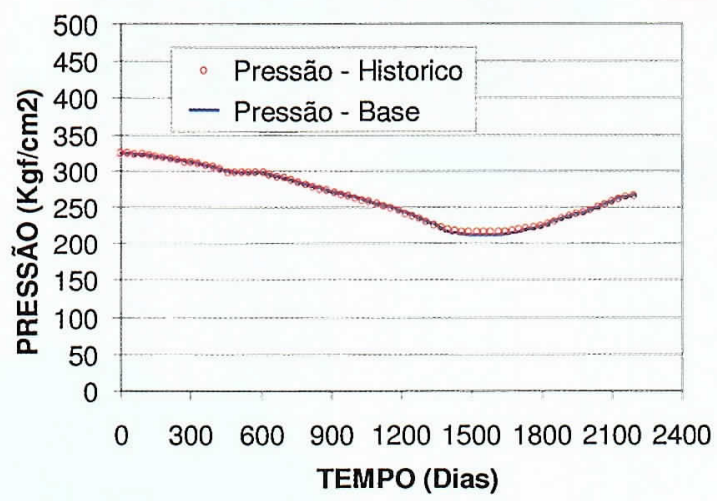

(b)

Figura 12 - Comportamento do campo.

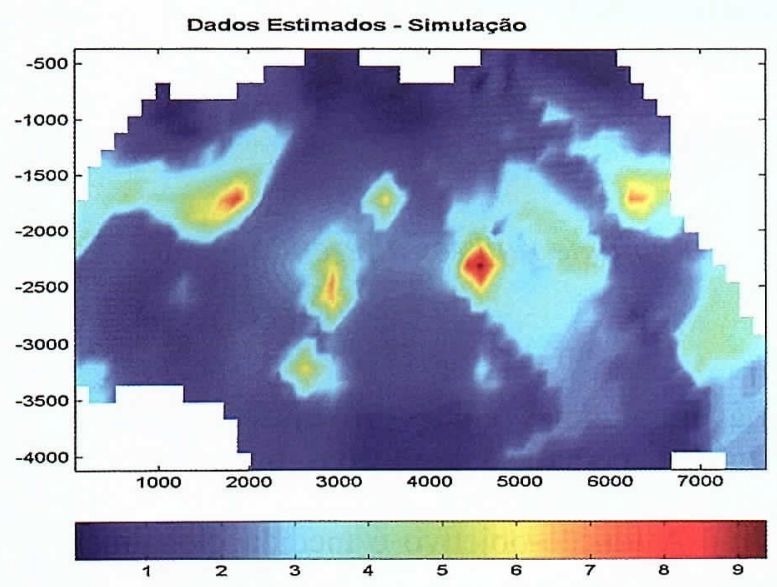

(a)

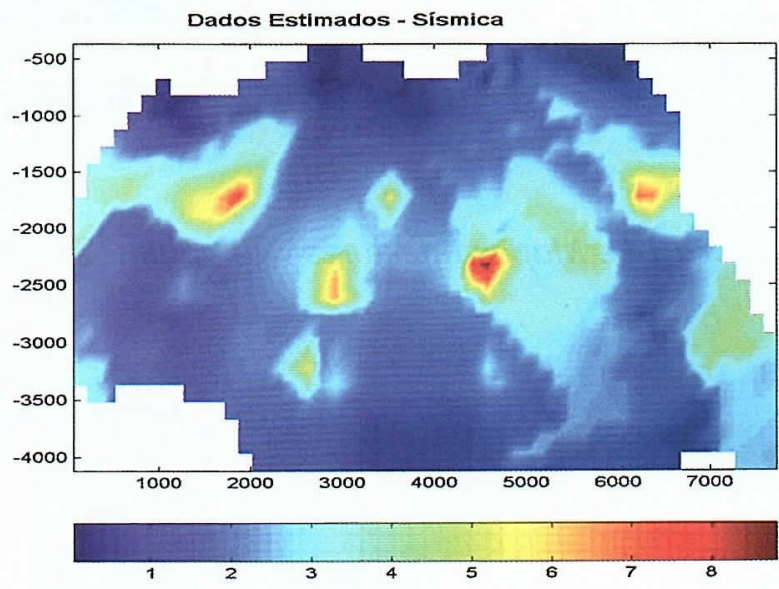

(b)

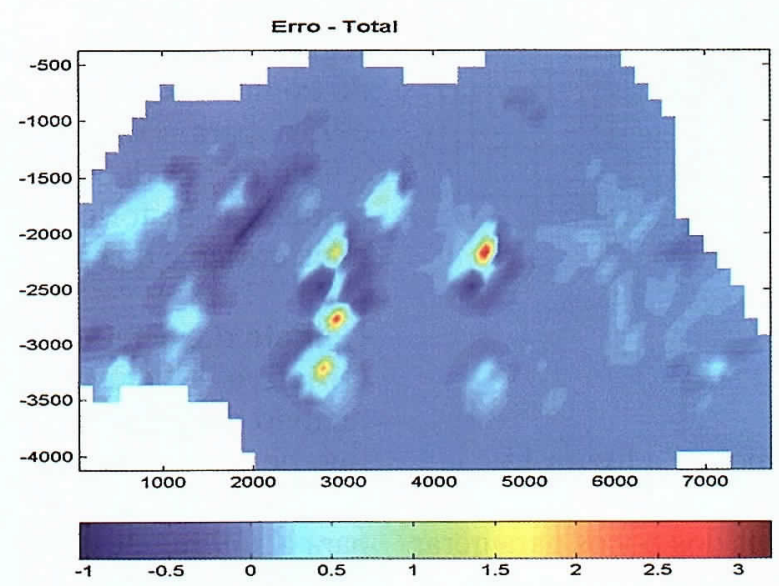

(c)

Figura 13 - Mapas superiores: (a) volume simulação (b) volume real (c) diferença. 


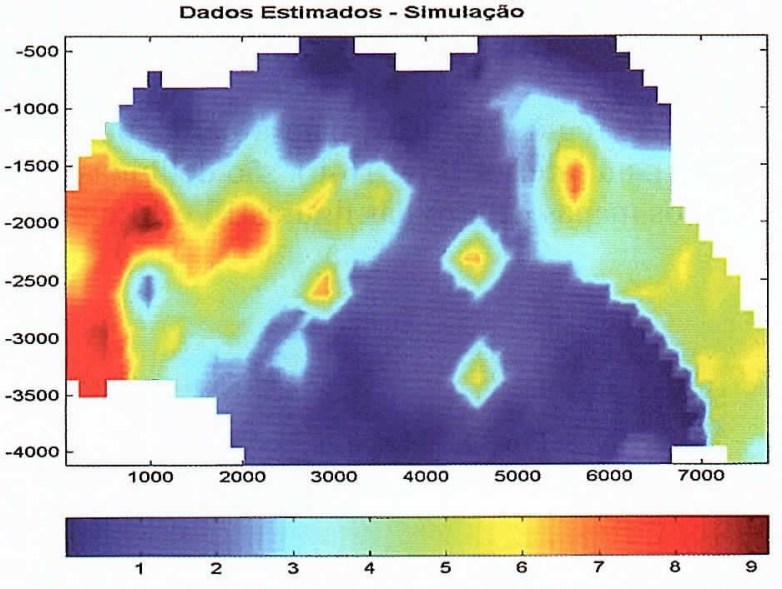

(a)

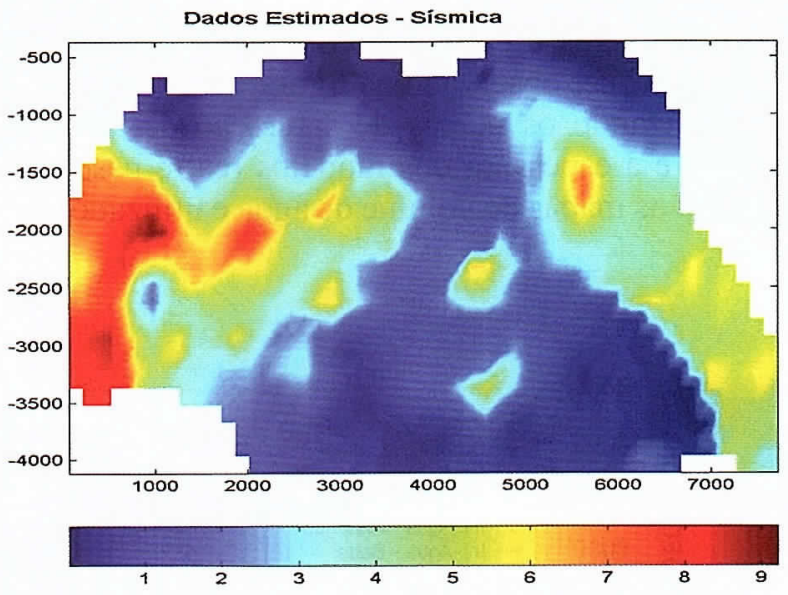

(b)

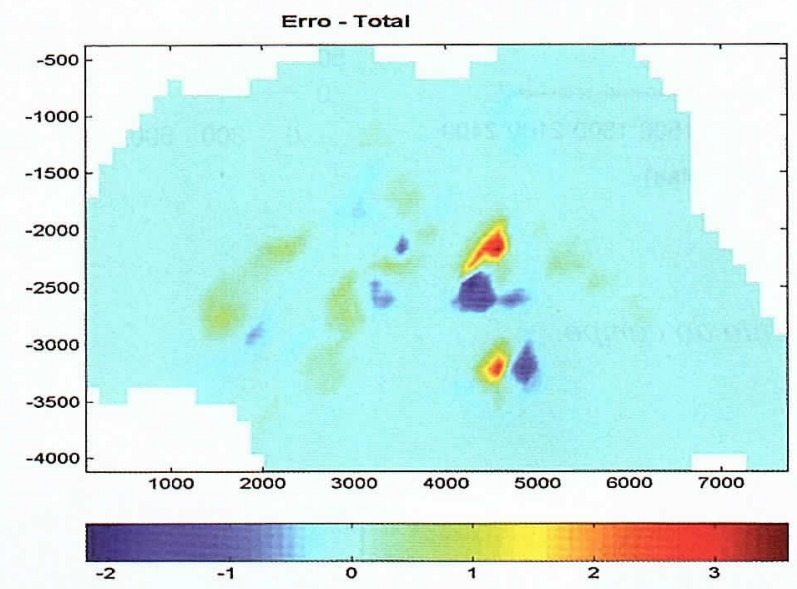

(c)

Figura 14 - Mapas inferiores: (a) volume simulação (b) volume real (c) diferença.

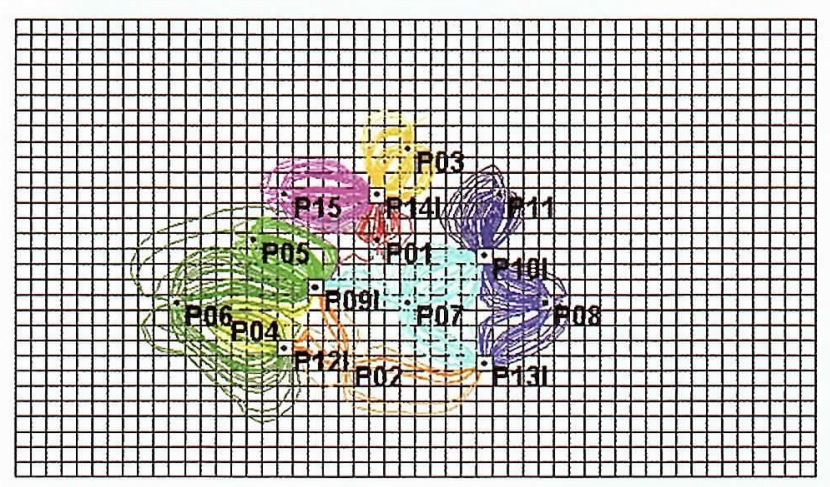

Figura 15 - Mapa de linhas de fluxo.

mapa de linhas de fluxo, como mostra a figura 15.

O modelo real é parcialmente conhecido, ou seja, são utilizadas as informações dos poços para gerar o modelo base, com isso a permeabilidade média do modelo base passa a ser conhecida. O problema maior passa a ser a identificação dos canais e das barreiras.

Para facilitar a análise e reduzir o número de variáveis, algumas regiões próximas e com mesmo erro no volume podem ser agrupadas, outras podem ser definidas individualmente.

A função-objetivo é medida globalmente (somatório dos poços e somatório das regiões), ou seja, o erro na produção, na injeção e na pressão é medido nos poços, já o erro na saturação de água é medido nas regiões. No cálculo da função-objetivo, o peso é definido como sendo 5\% para a produção, injeção e pressão e $95 \%$ para a saturação de água, porque como mostra a figura 12 os dados simulados estão ajustados se comparados ao histórico do campo, mostrando que o ajuste mais crítico é dos mapas de saturação.

Cálculo dos Efeitos das Regiões Críticas na FunçãoObjetivo Para o cálculo dos efeitos foi utilizado o método do planejamento estatístico (experimental) e o tipo de planejamento que demanda um menor número de simulações, considerando as 20 variáveis ( 9 regiões para Kx, 9 regiões para Kz e Kro e Krw) para o cálculo dos efeitos é o Plackett-Burman, onde foram necessárias 25 simulações para o cálculo dos efeitos. Foram analisadas 20 variáveis discretizadas em 3 níveis, como mostra a tabela 1 . 
Os multiplicadores para as permeabilidades absolutas variam de 0,5 a 1,5 e para a curvas de permeabilidades relativas variam de 0,5 a 1,0 para Kro e de 1,0 a 1,5 para Krw.

A montagem dos modelos de simulação segue uma combinação definida pela matriz do planejamento. Os efeitos de cada alteração podem ser observados na figura 17.

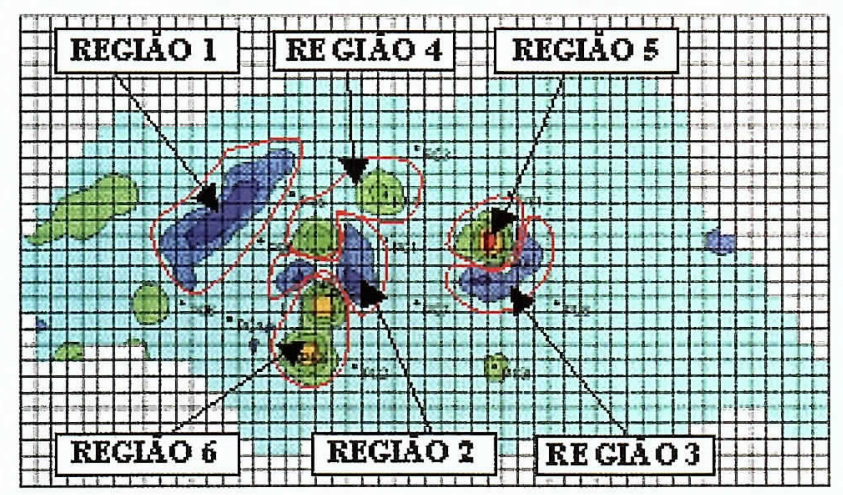

(a)
Através do primeiro planejamento é possível observar que dentre as alterações, as que apresentam maior efeito na função-objetivo são $\mathrm{Kx} 6$, Kro, $\mathrm{Kx} 8$, $\mathrm{Kx} 5$, Krw, Kx9, Kx7 e Kx3, sendo 6 alterações na permeabilidade horizontal e 2 alterações na permeabilidade relativa, a permeabilidade vertical não apresentou efeito significativo nesta etapa.

No processo de ajuste foram realizados 15 pla-

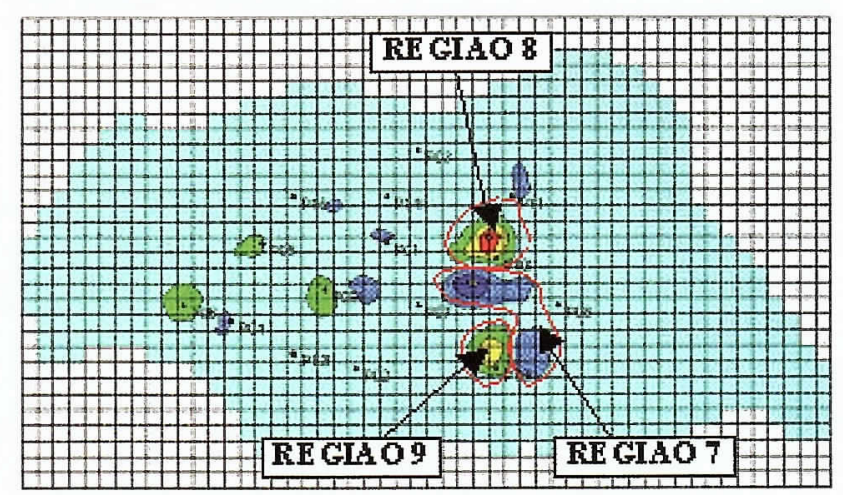

(b)

Figura 16 - Definição das regiões críticas: (a) diferença superior (b) diferença inferior.

Tabela 1 - Discretização para o 1º planejamento Plackett-Burman.

\begin{tabular}{|c|c|c|c|c|c|c|c|c|c|c|c|c|c|c|c|c|c|c|c|c|}
\hline Níve 1 & $\mathrm{Kx} 1$ & $\mathrm{~K} \times 2$ & $\mathrm{Kx} 3$ & $\mathrm{Kx} 4$ & $\mathrm{Kx} 5$ & Kx6 & $\mathrm{Kx} 7$ & $\mathrm{Kx} 8$ & Kx9 & $\mathrm{Kzl}$ & Kz2 & $\mathrm{K} z 3$ & $\mathrm{Kz} 4$ & Kz5 & $\mathrm{Kz} 6$ & Kz7 & Kz8 & Kz9 & Kro & Krw \\
\hline-1 & 0,5 & 0,5 & 0,5 & 0,5 & 0,5 & 0,5 & 0,5 & 0,5 & 0,5 & 0,5 & 0,5 & 0,5 & 0,5 & 0,5 & 0,5 & 0,5 & 0,5 & 0,5 & 0,50 & 1,00 \\
\hline 0 & 1,0 & 1,0 & 1,0 & 1,0 & 1,0 & 1,0 & 1,0 & 1,0 & 1,0 & 1,0 & 1,0 & 1,0 & 1,0 & 1,0 & 1,0 & 1,0 & 1,0 & 1,0 & 0,75 & 1,25 \\
\hline+1 & 1,5 & 1,5 & 1,5 & 1,5 & 1,5 & 1,5 & 1,5 & 1,5 & 1,5 & 1,5 & 1,5 & 1,5 & 1,5 & 1,5 & 1,5 & 1,5 & 1,5 & 1,5 & 1,00 & 1,50 \\
\hline
\end{tabular}

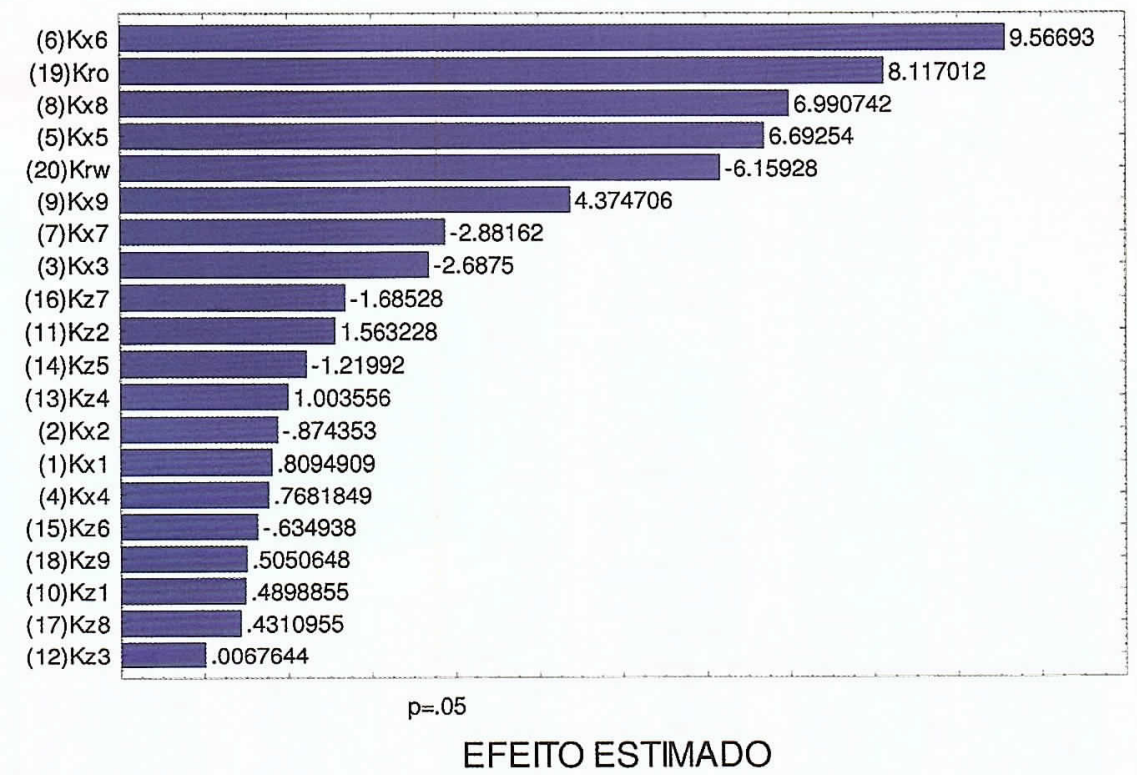

Figura 17 - Variáveis estatisticamente significativas para o 1ํ planejamento. 
nejamentos sendo 9 para o cálculo dos efeitos do tipo Plackett-Burman e 6 planejamentos para a obtenção dos meta-modelos (superfícies de respostas) que foram utilizados para substituir o simulador e encontrar os mínimos da função-objetivo, sendo 5 planejamentos do tipo Fatorial Completo e 1 planejamento do tipo Box-Behnken que é apresentado a seguir. Maiores informações sobre a utilização de planejamento estatístico no processo de ajuste pode ser encontrada em Risso (2007).

Obtenção de Meta-Modelos (Superfície de Resposta) Na última etapa do processo, quando já se obteve uma faixa próxima ao mínimo, foi realizado um planejamento do tipo Box-Behnken, procurando-se assim identificar de forma mais precisa os valores que minimizam a função-objetivo, ou seja, que reduzem o erro entre os mapas de saturação e entre os dados do histórico de campo.

O planejamento foi aplicado em cinco regiões, onde foram estudadas 6 variáveis discretizadas em 3 níveis (multiplicadores), como mostra a tabela 2 .

O coeficiente de correlação foi de 0,99 e o $\mathrm{F}$ calculado foi superior ao $\mathrm{F}$ tabelado para $95 \%$ de confiança, com isso a superfície de resposta é válida e é possível então obter a equação (7) com comportamento quadrático e os valores de $\mathrm{Kx}, \mathrm{Kz}$ e Krw são codifica-
Tabela 2 - Discretização para o $15^{\circ}$ planejamento BoxBehnken.

\begin{tabular}{ccccccc}
\hline Nível & $\mathrm{Kx} 5$ & $\mathrm{Kx6}$ & $\mathrm{Kx7}$ & $\mathrm{Kz1}$ & $\mathrm{Kz3}$ & $\mathrm{Krw}$ \\
\hline-1 & 0,00 & 0,50 & 0,00 & 0,50 & 0,50 & 0,70 \\
0 & 0,25 & 1,00 & 0,25 & 1,00 & 1,50 & 0,90 \\
+1 & 0,50 & 1,50 & 0,50 & 1,50 & 2,50 & 1,10 \\
\hline
\end{tabular}

dos e podem variar entre $-1,00$ e $+1,00$.

Através da análise da figura 18 é possível uma melhor visualização do comportamento das variáveis.

Analisando-se todas as combinações, verificase que o erro reduz quando a permeabilidade das Regiões 5,6 e 7 diminui e o multiplicador da curva de permeabilidade relativa (Krw) está entre 0,8 e 0,9 . O mínimo encontrado pela superfície de resposta foi 0,03 , menor que a tolerância mínima exigida de $0,05(5 \%)$, com isso o processo de ajuste foi concluído. Os valores que minimizam a função são: $\mathrm{Kx} 5=-1,00 *$ (multiplicador $=0,00) ; \mathrm{Kx} 6=-0,60 *$ (multiplicador $=0,70), \mathrm{Kx} 7$ $=-1,00^{*}$ (multiplicador $=0,00$ ), Kz1 $=-0,60^{*}$ (multiplicador $=0,70), \mathrm{Kz} 3=0,60 *($ multiplicador $=2,10) \mathrm{e}$ $\mathrm{Krw}=-0,20 *$ (multiplicador $=0,86$ ).

$$
\varepsilon=\left[\begin{array}{l}
41,42+4,91 \times(K x 5)-2,82 \times(K x 5)^{2}+2,07 \times(K x 6)+1,19 \times(K x 6)^{2}+2,62 \times(K x 7)+0,56 \times(K x 7)^{2}+ \\
0,34 \times(K z 1)+0,09 \times(K z 1)^{2}-1,95 \times(K z 3)+1,22 \times(K z 3)^{2}+5,39 \times(K r w)+12,69 \times(K r w)^{2}- \\
0,04 \times(K x 5) \times(K x 6)+0,46 \times(K x 5) \times(K x 7)+0,01 \times(K x 5) \times(K z 1)-0,22 \times(K x 5) \times(K z 3)- \\
0,48 \times(K x 5) \times(K r w)+0,05 \times(K x 6) \times(K x 7)+0,06 \times(K x 6) \times(K z 1)+0,02 \times(K x 6) \times(K z 3)+ \\
1,82 \times(K x 6) \times(K r w)+0,24 \times(K x 7) \times(K z 1)+0,01 \times(K x 7) \times(K z 3)+0,54 \times(K x 7) \times(K r w)+ \\
0,08 \times(K z 1) \times(K z 3)-0,24 \times(K z 1) \times(K r w)+0,21 \times(K z 3) \times(K r w)
\end{array}\right] x(E-03)
$$

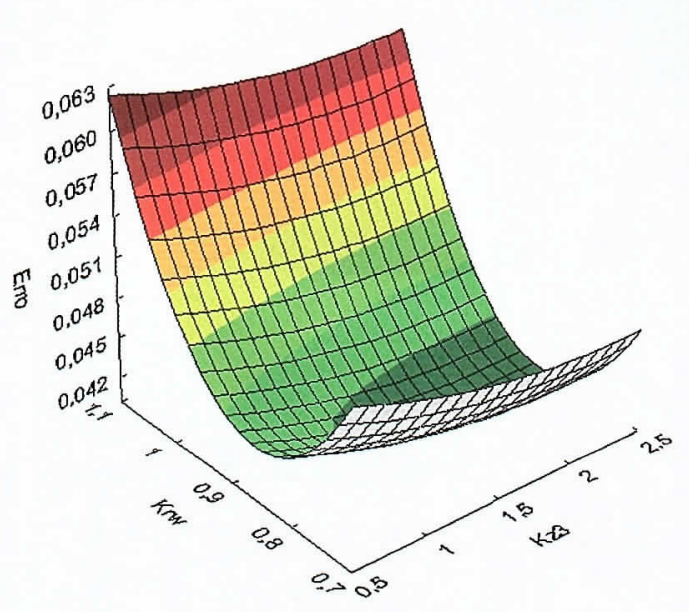

(a)

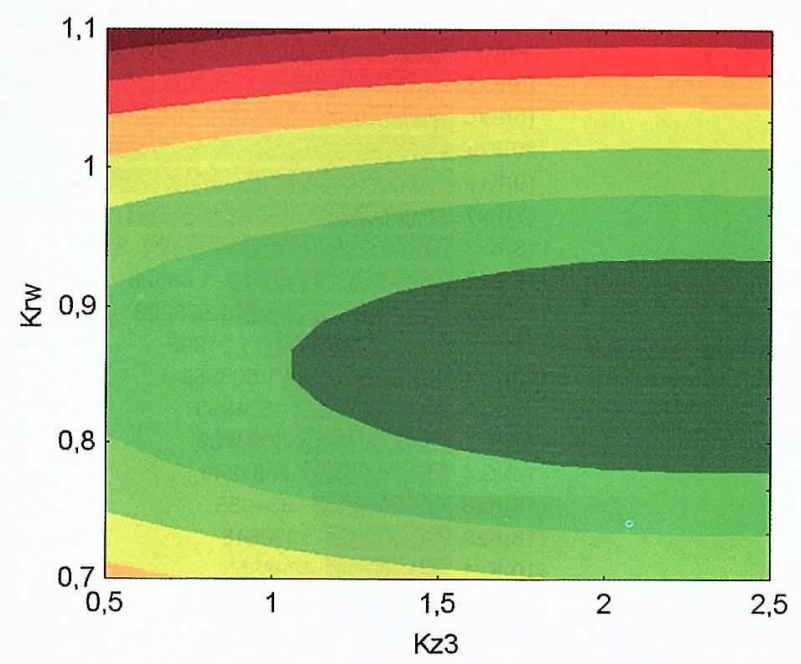

(b)

Figura 18 - Comportamento do erro na parte superior para o $15^{\circ}$ planejamento: (a) superficie de resposta (b) curvas de contorno - (Kz3 versus Krw). 
Modelo Ajustado Analisando-se as superfícies de respostas observamos que uma ou mais regiões (faixa) minimizam as funções-objetivos (erro), o que demonstra certa incerteza na definição exata do atributo, sendo que múltiplos modelos podem ser construídos com respostas semelhantes, porém, o modelo ajustado, o qual será comparado com os resultados obtidos pelo modelo real, foi construído através dos mínimos encontrados através das superfícies de respostas dos planejamentos. O erro da parte superior do reservatório pode ser observado na figura 19 e da parte inferior na figura 20 .

$O$ erro inicial da parte superior do modelo base era de 46,99 e após o ajuste o erro reduziu para 0,96 , ou seja, $2,05 \%$ do erro inicial. Para a parte inferior o erro inicial era de 77,75 e após o ajuste o erro reduziu para 1,92 , ou seja, $2,47 \%$ do erro inicial. Considerando os dois mapas o erro inicial era de 62,37 e após o ajuste o erro reduziu para 1,44 , ou seja, $2,31 \%$ do erro inicial.

Analisando-se os resultados da figura 19 conclui-se que os resultados do modelo ajustado são muito próximos do modelo real. Considerando somente o ajuste global, observamos que identificou-se os canais de fluxo e as barreiras. A identificação dos canais e das barreiras foi melhor na parte inferior do reservatório, devido ao maior avanço das frentes de saturação provocadas pelo aqüífero, enquanto que na parte superior a identificação ficou prejudicada, o que poderia ser solucionado através da obtenção de um novo mapa de saturação em um tempo futuro.

Observa-se que a permeabilidade absoluta do modelo ajustado e do modelo real também está muito próxima, conforme mostra a figura 21 para a permeabilidade horizontal para a parte superior do reservatório e a figura 22 para a parte inferior.

Observa-se também que a permeabilidade vertical do modelo ajustado e do modelo real também está muito próxima, conforme mostra a figura 23 para a parte superior do reservatório e a figura 24 para a parte inferior.

A figura 25 mostra as curvas de permeabilidades relativas. A confiabilidade do modelo numérico pode ser verificada através da previsão do comportamento futuro do campo (Fig. 26).

A medição do erro globalmente (somatório das regiões alteradas) conseguiu captar os erros principais, mas um ajuste local poderia refinar mais o ajuste e identificar algumas regiões menores que não foram identificadas globalmente. Já outras regiões, principalmente na

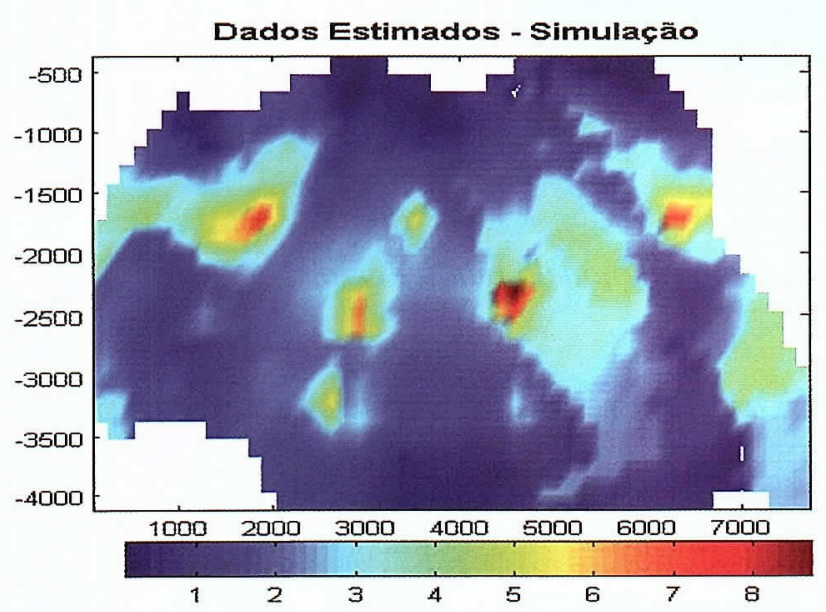

(a)

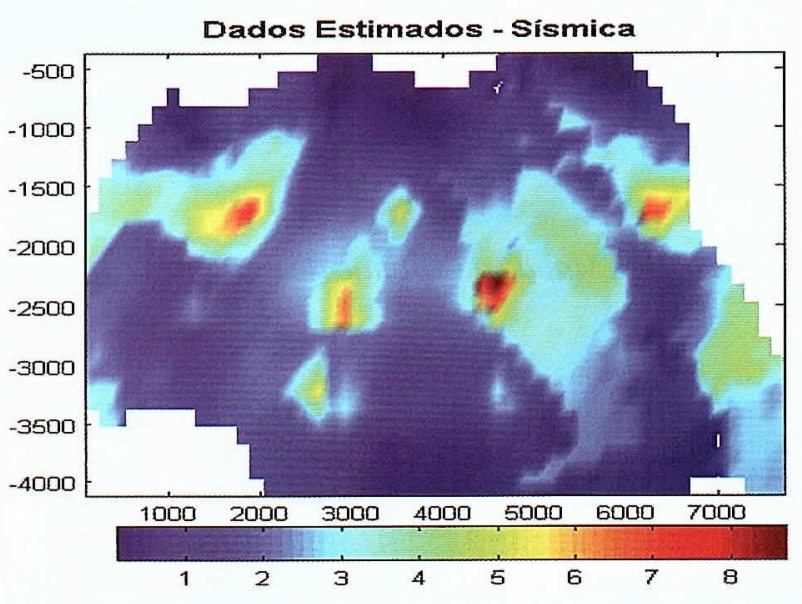

(b)

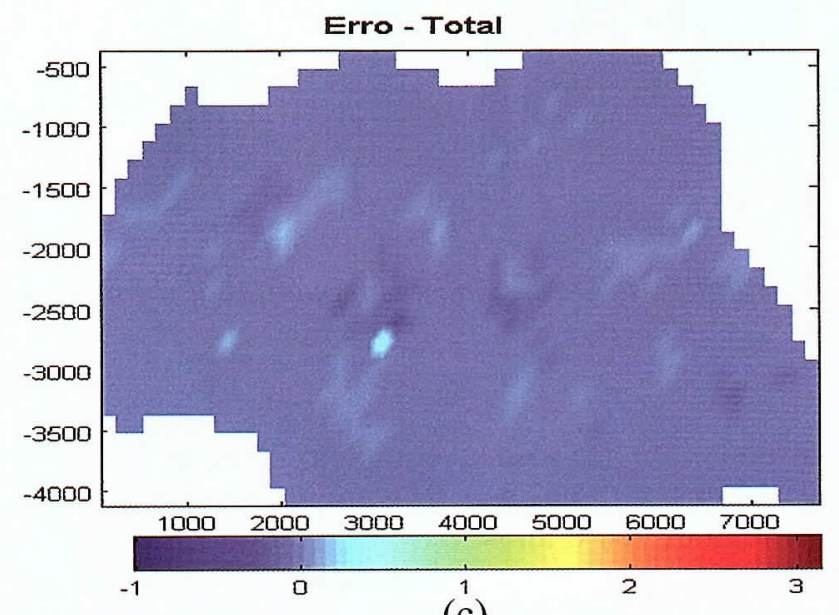

(c)

Figura 19 - Mapas de volume de água/m²: (a) modelo ajustado (b) modelo real (c) erro. 


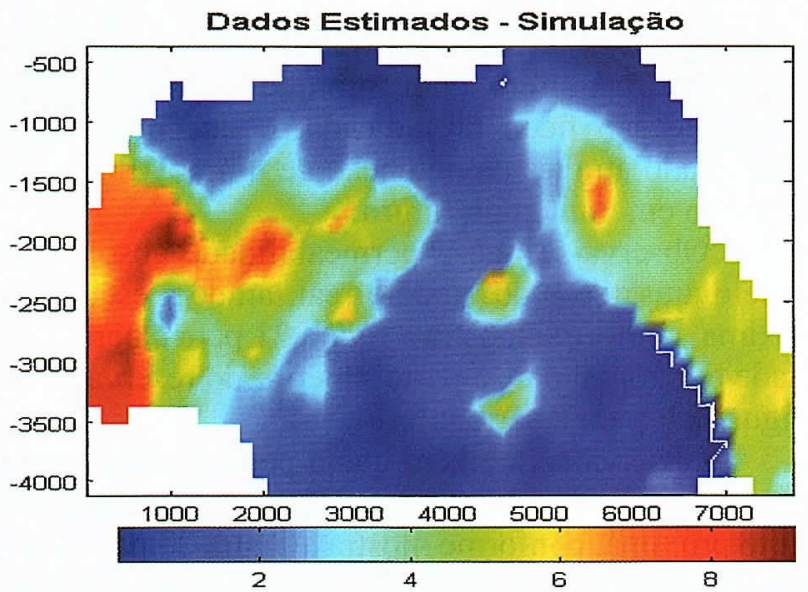

(a)

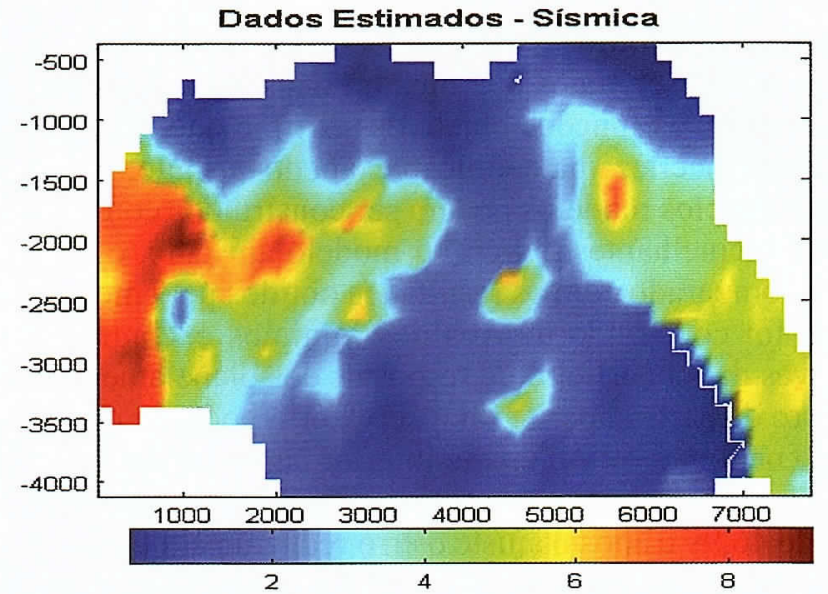

(b)

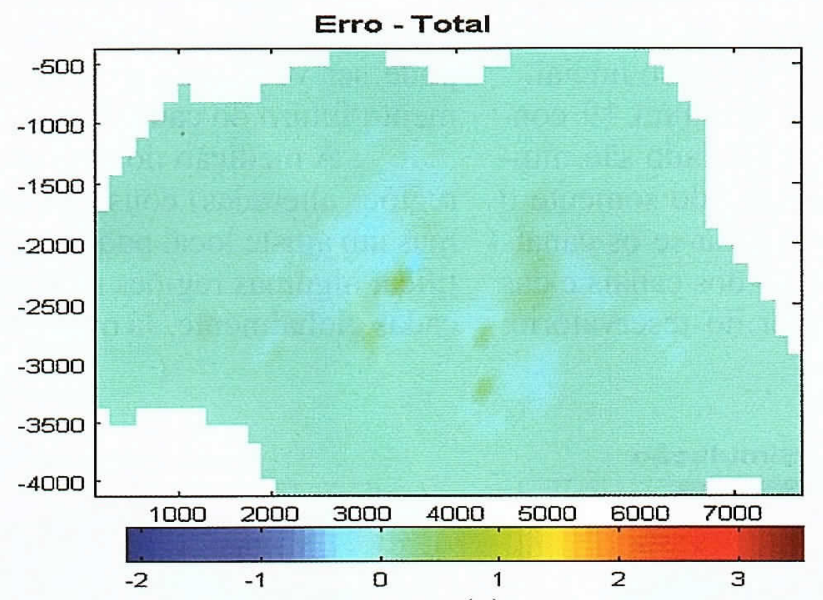

(c)

Figura 20 - Mapas de volume de água/m²: (a) modelo ajustado (b) modelo real (c) erro.

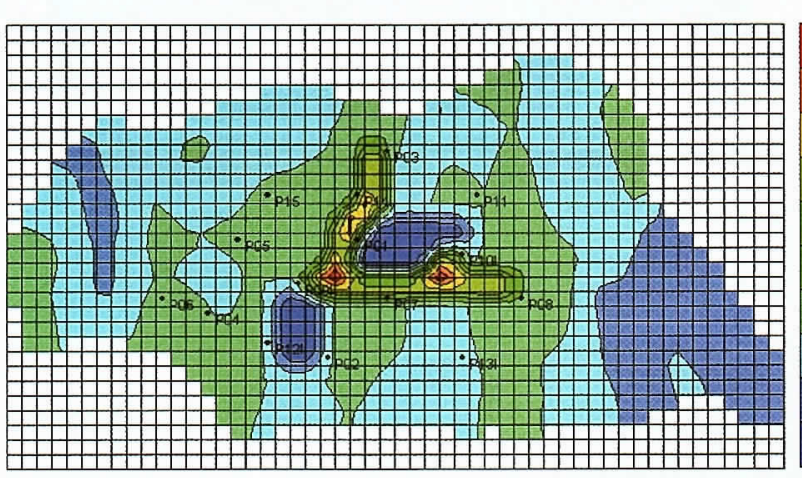

(a)

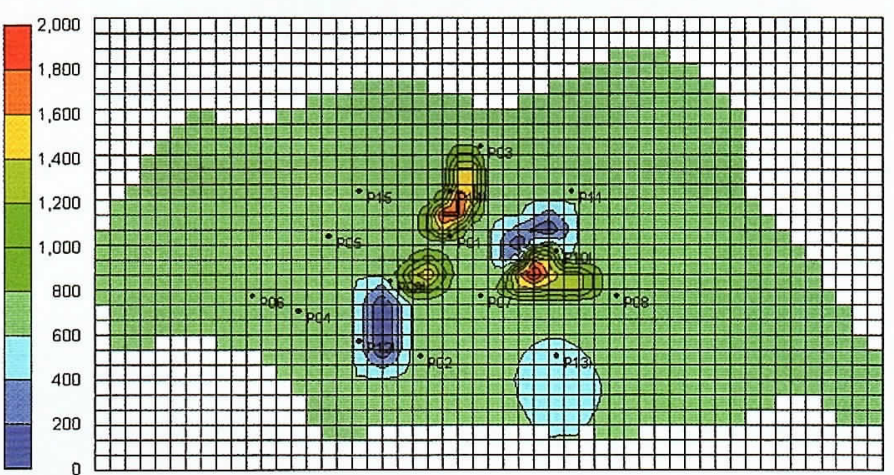

(b)

Figura 21 - Mapa superior da permeabilidade horizontal: (a) modelo real (b) modelo ajustado.

parte superior do reservatório não poderiam ser identificadas mesmo com ajuste local, porque a frente de saturação ainda não chegou nestas regiões aos 6 anos de produção.

Foram realizadas 353 simulações, distribuídas em 15 planejamentos estatísticos, sendo nove planejamentos Plackett-Burman, um planejamento fatorial completo $2^{5}$, quatro planejamentos fatoriais completos $2^{3}$ e um planejamento Box-Behnken.

A produção acumulada de óleo $(\mathrm{Np})$ do modelo real modificado após a previsão é de 32,8 milhões de $\mathrm{m}^{3}$, enquanto que do modelo base é de 38,9 milhões de $\mathrm{m}^{3}$, uma diferença de 6,1 milhões de $\mathrm{m}^{3}$, ou um erro de $18,6 \%$, já após o ajuste o modelo produziu 33,8 milhões 


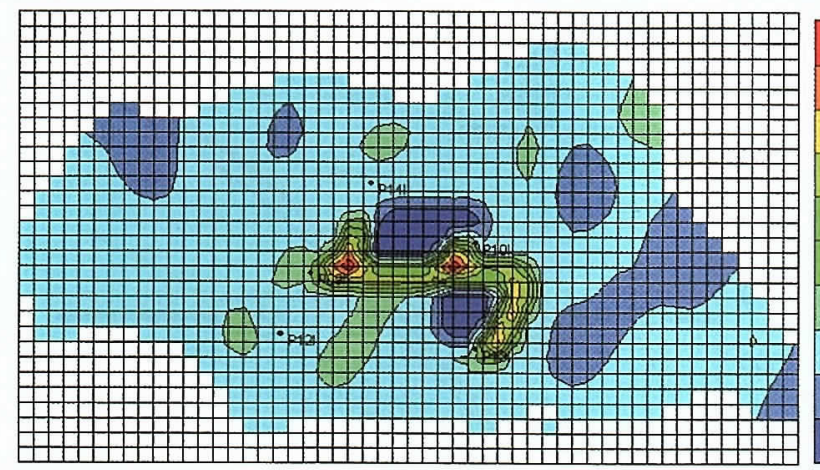

(a)

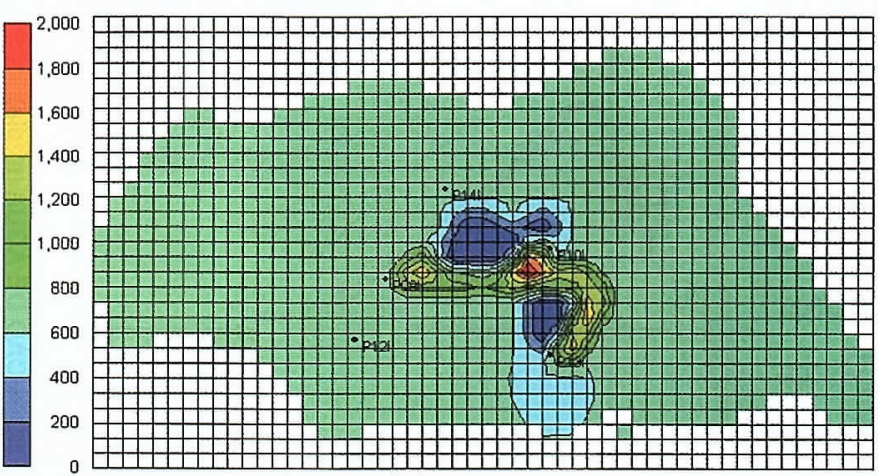

(b)

Figura 22 - Mapa inferior da permeabilidade horizontal: (a) modelo real (b) modelo ajustado.

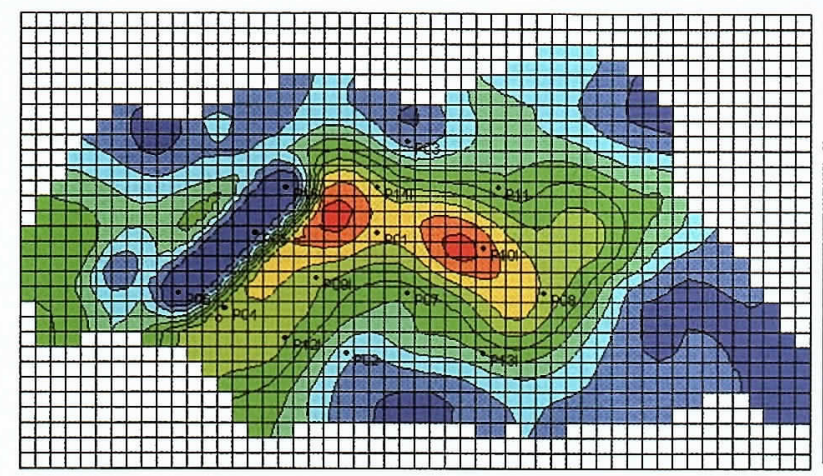

(a)

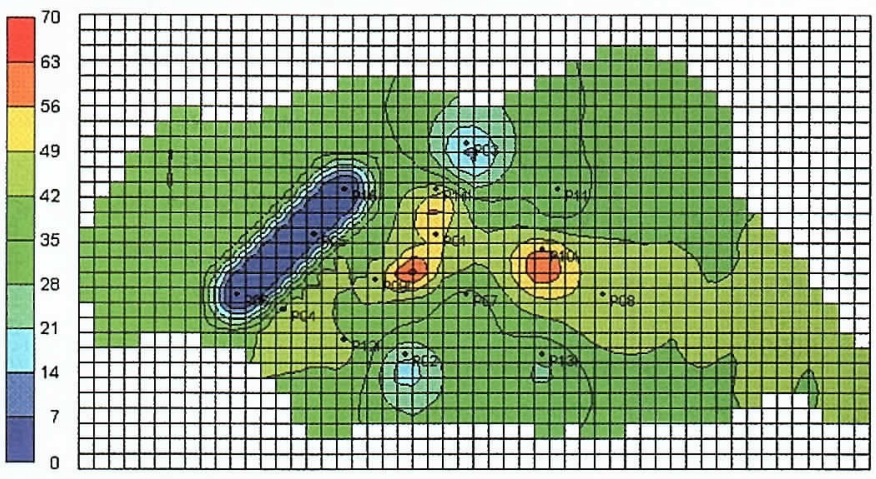

(b)

Figura 23 - Mapa superior da permeabilidade vertical: (a) modelo real (b) modelo ajustado.

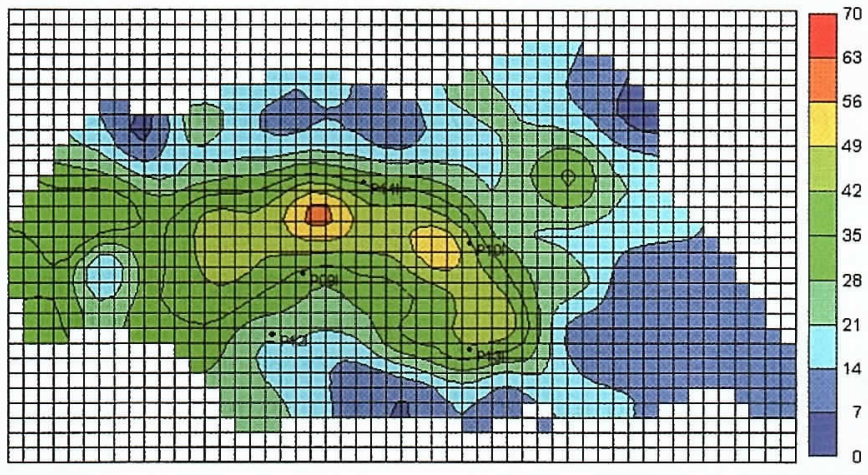

(a)

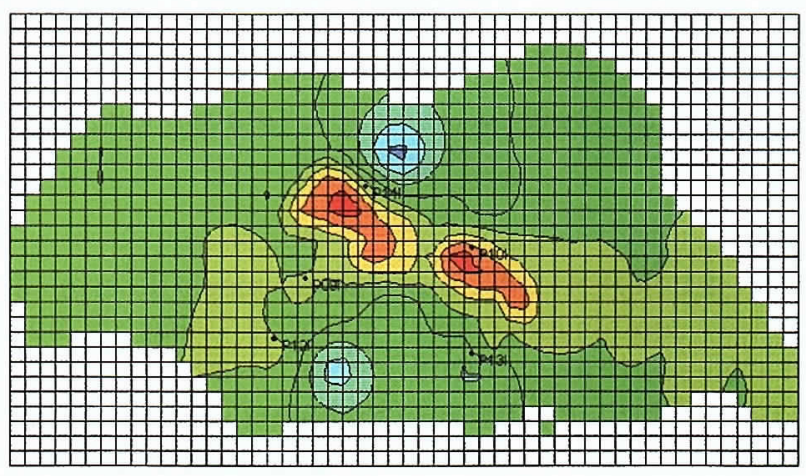

(b)

Figura 24 - Mapa inferior da permeabilidade horizontal: (a) modelo real (b) modelo ajustado.

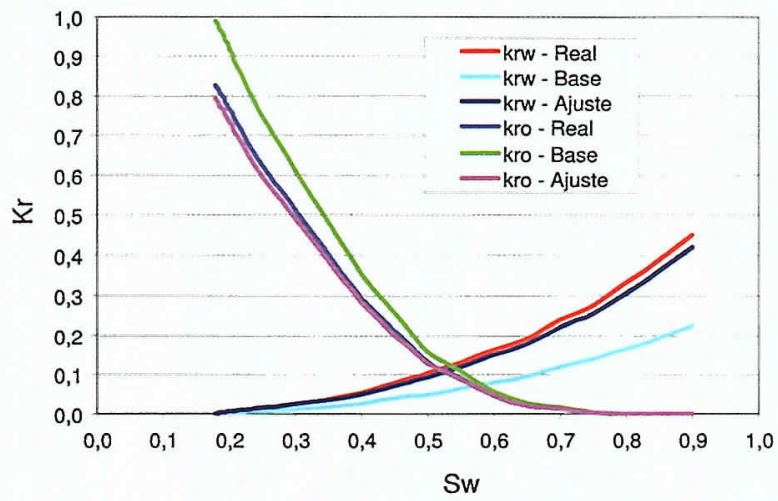

Figura 25 - Curvas de permeabilidade relativa. de $\mathrm{m}^{3}$, uma diferença de 1 milhão de $\mathrm{m}^{3}$, ou seja, o erro reduziu para $3 \%$.

A produção acumulada de água $(\mathrm{Wp})$ do modelo real modificado após a previsão é de 25,5 milhões de $\mathrm{m}^{3}$, enquanto que do modelo base é de 12,6 milhões de $\mathrm{m}^{3}$, uma diferença de $-12,9$ milhões de $\mathrm{m}^{3}$, ou um erro de $-50,6 \%$, já após o ajuste o modelo produziu 23,4 milhões de $\mathrm{m}^{3}$, uma diferença de $-2,1$ milhões de $\mathrm{m}^{3}$, ou seja, o erro reduziu para $-8,2 \%$.

Estes resultados, juntamente com o erro dosmapas de saturação mostram que a incorporação dos mapas de saturação como informação adicional foi fundamental nesse processo de ajuste. 


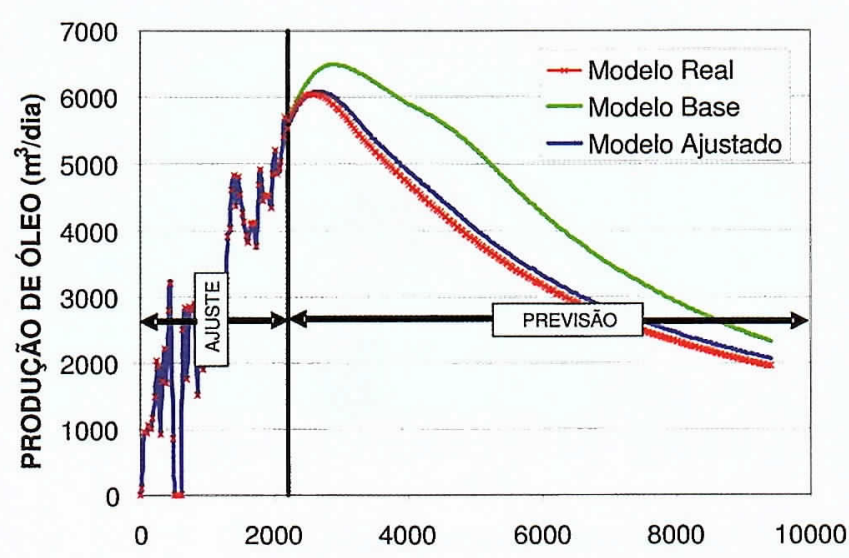

(a)

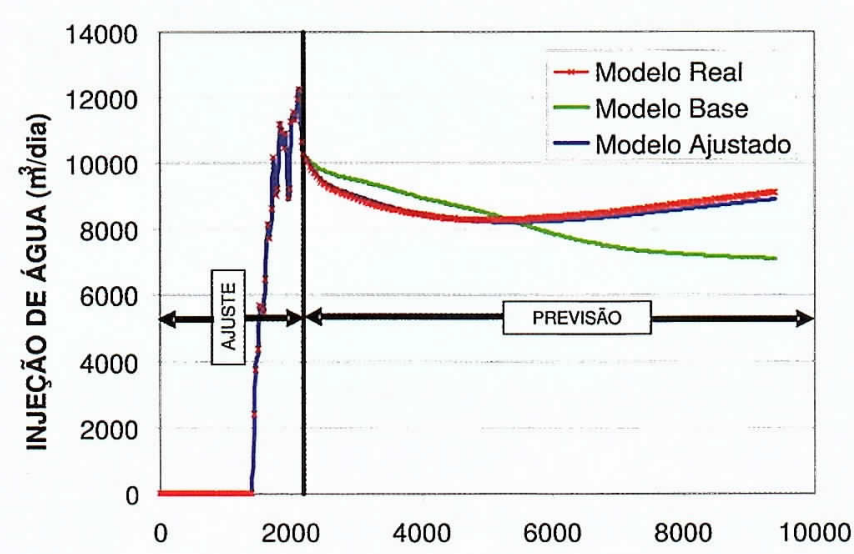

(c)

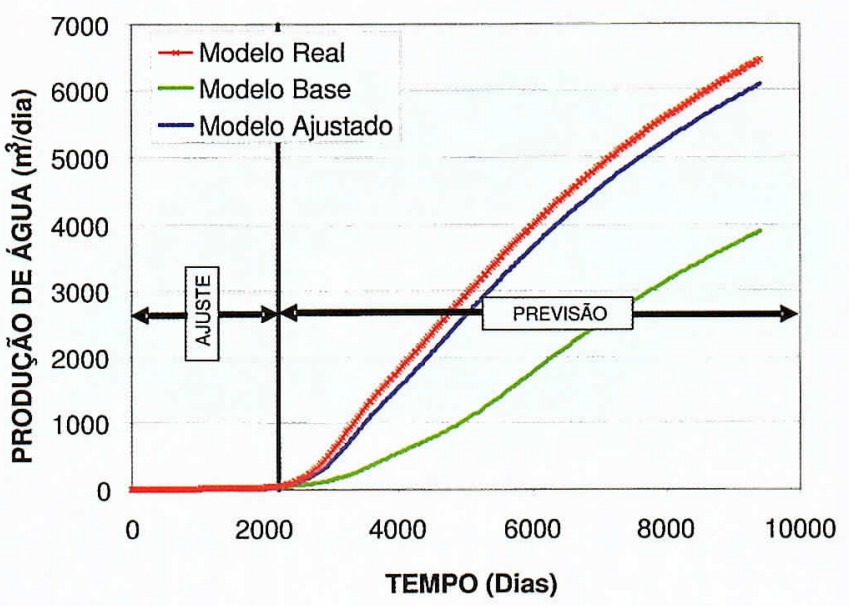

(b)

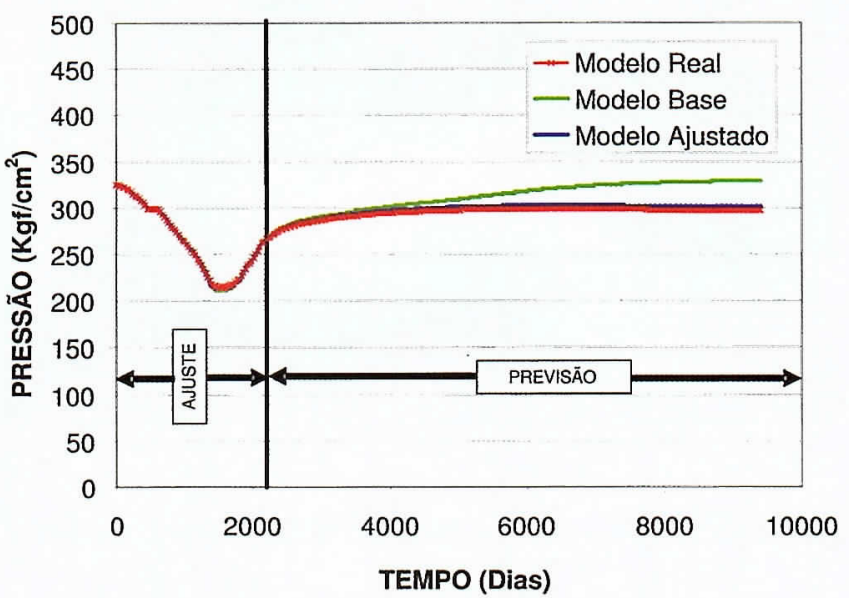

(d)

Figura 26 - Previsão do campo: (a) produção de óleo (b) produção de água (c) injeção de água (d) pressão.

CONCLUSÕES A utilização do mapa de erro (diferença) combinado com o mapa de linhas de fluxo mostrou-se eficaz na identificação das regiões críticas do reservatório, mesmo necessitando de alguns ajustes (redefinição das regiões) no decorrer do processo de ajuste.

O ajuste dos mapas de volume de água por unidade de área mostrou-se eficaz, pois o foco do ajuste ficou voltado para as regiões mais críticas do reservatório, aquelas que realmente afetavam a produção do campo.

O método desenvolvido mostrou-se eficaz para a utilização de atributos com comportamento local (permeabilidades absolutas verticais e horizontais), bem como para atributos que tem comportamento global (curvas de permeabilidade relativa). $\mathrm{O}$ ajuste global (erro medido no campo todo) mostrou-se eficaz, porém algumas pequenas regiões críticas não foram identificadas principalmente na parte superior do reservatório. Neste caso mesmo um ajuste local não poderia identificá-las, porque as frentes de saturação de água ainda não chegaram nestas regiões críticas, a identificação só seria possível caso o ajuste com a obtenção de um novo mapa de saturação fosse feito em um período futuro.

No processo de ajuste a função-objetivo foi minimizada, reduzindo-se o erro para aproximadamente $2 \%$ do erro inicial. Com isso mostrou-se que com a utilização das informações de mapas de saturação no processo de ajuste pode-se obter modelos numéricos de campos de petróleo mais confiáveis, visto que a grande dificuldade do ajuste se dá no início do desenvolvimento do campo, onde as informações do avanço de água tais como a chegada em poços produtores ainda são insuficientes. Mesmo que o processo de ajuste seja dificultado pelo aumento do número de atributos críticos, é viável realizar a tarefa com eficácia utilizando o planejamento estatístico e a superfície de resposta e em muitos casos até reduzindo o número de simulações necessárias no processo de ajuste de histórico do campo.

Agradecimentos Os autores gostariam de agradecer ao UNISIM, CAPES, ANP, FINEP (CTPETRO), PETROBRAS, CEPETRO/Unicamp e o Departamento de Engenharia de Petróleo (FEM - Unicamp) pelo suporte para a realização deste trabalho. 


\section{Referências}

Aanonsen S.I., Aavatsmark I., Barkve T., Cominelli A., Gonard R., Gosselin O., Kolasinski M., Reme H., Effect of Scale Dependent Data Correlations in an Integrated History Matching Loop Combining Production Data and 4D Seismic Data. In: SPE Reservoir Simulation Symposium, Houston, Texas, Paper SPE 79665, CDRom.

Al-Jenaibi M., Soroka W.L., Al-Jeelani A.B., Hafez H.H., Kleiss E., Melville P. 2006. 4D Seismic Monitors Fluid Changes Over Time in a Carbonate Reservoir. In:Abu Dhabi International Petroleum Exhibition and Conference, Abu Dhabi, UAE, Paper SPE 100479, CDRom.

Arenas E., Kruijsdijk C. V., Oldenziel T. 2001. "SemiAutomatic History Matching Using the Pilot Point Method Including Time-Lapse Seismic Data". In: SPE Annual Technical Conference and Exhibition, New Orleans, Louisiana, Paper SPE 71634, CD-Rom.

Arts R., Brouwer J., Hofstee C., Kooijman J., Drijkoningen G. 2006. Continuous 4D Monitoring is Now Reality". In: Intelligent Energy Conference and Exhibition, Amsterdam, The Netherlands, Paper SPE 99927, CDRom.

Blonk B., Calvert R.W., Koster J.K., Van Der Zee G. 1998. Assessing the Feasibility of a 4D Seismic Reservoir Monitoring Project". In: European Petroleum Conference, The Hague, Netherlands, Paper SPE 50666, CD-Rom.

Castro S., Caers J., Otterlei C., Høye T., Andersen T., Gomel P. 2006. "A Probabilistic Integration of Well Log, Geological Information, 3D/4D Seismic, and Production Data: Application to the Oseberg Field". In: SPE Annual Technical Conference and Exhibition, San Antonio, Texas, USA, Paper SPE 103152, CD-Rom.

Cordeiro R. 2002. Sísmica a serviço da produção. Brasil Energia, 263:38-40.

COMPUTER MODELLING GROUP. 2005. IMEX User's Manual. Alberta, Canada, Calgary, 617 p.

Dong Y. \& Oliver D.S. 2003. "Quantitative Use of 4D Seismic Data for Reservoir Description”. In: SPE Annual Technical Conference and Exhibition, Denver, Colorado, Paper SPE 84571, CD-Rom.

Guerillot D. \& Pianelo L. 2000. Simultaneous Matching of Production Data and Seismic Data for Reducing Uncertainty in Production Forecasts. In: SPE European Petroleum Conference, Paris, France, Paper SPE 65131, CD-Rom.

Hoffman B.T. \& Caers J. 2003. Geostatistical History Matching Using a Regional Probability Perturbation Method. In: SPE Annual Technical Conference and Exhibition, Denver, Colorado, Paper SPE 84409, CDRom.

Khan M., Waggoner J.R., Hughes J.K. 2000. 4D Cause and Effect: What do reservoir fluid changes look like on seismic? In: SPE Annual Technical Conference and Exhibition, Dallas, Texas, Paper SPE 63132, CD-Rom.

Kretz V., Ravalec-Dupine M., E Roggero F. 2002. An Integrated Reservoir Characterization Study Matching
Production Data and 4D Seismic. In: SPE Annual Technical Conference and Exhibition, San Antonio, Texas, Paper SPE 77516, CD-Rom.

Kretz V., Valles B., Sonnelan, L. 2004. Fluid Front History Matching Using 4D Seismic and Streamline Simulation. In: SPE Annual Technical Conference and Exhibition, Houston, Texas, Paper SPE 90136, CD-Rom.

Lumley D.E. 1994. 4D Seismic Monitoring of Reservoir Fluid-Flow Processes. In: SPIE Conference, San Diego, EUA, CD-Rom.

Lumley D.E., Strandenes S., Dvorkin J., Packwood J. 1994. Seismic Monitoring of Oil Production: A Feasibility Study. In: SEG Conference, Los Angeles, EUA, CDRom.

Lumley D.E., Bee M., Jenkins S., Wang Z. 1995. 4-D Seismic Monitoring of an Active Steamflood. In: Annual International SEG Conference, Houston, EUA, CDRom.

Mantica S., Cominelli A., Mantica G., Dell'insubria U. 2002. Combining Global and Local Optimization Techniques for Automatic History Matching Production and Seismic Data. SPE Journal, 7(2):123-130. (Paper SPE 78353).

Mezghani M., Fornel A., Langlais V., Lucet N. 2004. History Matching and Quantitative Use of 4D Seismic Data for an Improved Reservoir Characterization. In: SPE Annual Technical Conference and Exhibition, Houston, Texas, Paper SPE 90420, CD-Rom.

Mitra P.P. \& Singh K. 2003. 4D Seismic in Mapping the Change in Fluid Phase in Carbonate: A Case Study. In: SPE Asia Pacific Oil and Gas Conference and Exhibition, Jakarta, Indonesia, Paper SPE 80552, CD-Rom.

Ribeiro N., Steagall D., Oliveira R., Formiga L., Kerber P., Jaeger M. 2005. Challenges of the 4D Seismic in the Reservoir Management of Marlim Field. In: SPE Latin American and Caribbean Petroleum Engineering Conference, Rio de Janeiro, Brazil, Paper SPE 94905, CD-Rom.

Risso V.F. 2007. Ajuste de Histórico Utilizando Planejamento Estatístico e Combinação de Dados de Produção, Pressão e Mapas de Saturação. Tese de Doutoramento em Ciências e Engenharia de Petróleo, UNICAMP, Campinas, 263p.

Skorstad A., Kolbjørnsen O., Drottning Å., Gjøystdal H., Huseby O. 2006. Combining Saturation Changes and 4D Seismic for Updating Reservoir Characterizations". SPE Reservoir Evaluation \& Engineering, Volume 9(5):502512. (Paper SPE 106366).

Steagall D.S., Gomes J.A.T., Oliveira R.M., Ribeiro N.M.S.J., Queiroz R.Q., Carvalho M.R.J., Souza C.Z. 2005. How To Estimate the Value of the Information (VOI) of a 4D Seismic Survey in One Offshore Giant Field. In: SPE Annual Technical Conference and Exhibition, Dallas, Texas, Paper SPE 95876, CD-Rom.

Manuscrito BR 14

Submetido em 21 de dezembro de 2007 Aceito em 10 de março de 2008 